\title{
One-dimensional electronic systems: metal-chain complexes and organic conductors
}

$\operatorname{AUTHOR}(S)$ :

Yoshida, Yukihiro; Kitagawa, Hiroshi

\section{CITATION:}

Yoshida, Yukihiro ...[et al]. One-dimensional electronic systems: metal-chain complexes and organic conductors. Chemical Communications 2020, 56(70): 10100-10112

ISSUE DATE:

2020-09-11

URL:

http://hdl.handle.net/2433/255599

\section{RIGHT:}

This is the accepted manuscript of the article, which has been published in final form at

https://doi.org/10.1039/DOCC04124F.; The full-text file will be made open to the public on 11 September 2021 in accordance with publisher's 'Terms and Conditions for Self-Archiving'.; This is not the published version. Please cite only the published version.; この論文は出版社版でありません。引用の際には出版社版をご確認ご利用ください。 


\section{FEATURE ARTICLE}

\section{One-Dimensional Electronic Systems: Metal-Chain Complexes and Organic Conductors}

Received 00th January 20xx, DOI: $10.1039 / x 0 x x 00000 x$ Accepted 00th January 20xx

\begin{abstract}
Yukihiro Yoshida*a and Hiroshi Kitagawa*a
One-dimensional (1D) metal-chain complexes and organic conductors show many similarities as well as striking differences in structural and electronic properties, although constituent elements and orbitals that contribute to charge transfer in these systems are quite different. In this review, we highlighted the structural and electronic properties of neutral MMX-chain complexes $\left(\mathrm{M}=\mathrm{Pt}^{2+/ 3+}, \mathrm{X}=\mathrm{I}^{-}\right)$and tetramethyltetrathiafulvalene-based cation radical salts as typical examples of each group while comparing them with each other. This review primarily aims to construct a coherent body of knowledge of 1D electronic materials that might have been separately investigated. We have proposed future directions for the exploration of new and more advanced electronic materials not only having 1D character, but also residing in the dimensional crossover regime.
\end{abstract}

\section{Introduction}

Intuitively, one-dimensional (1D) electronic systems seem to be extremely simple, but they have long been a central subject in solid-state sciences because of their totally different chemistry and physics from those of their higher-dimensional counterparts. ${ }^{1-3}$ This is primarily because these systems offer a rich variety of exotic quantum phenomena such as charge/spinsoliton, polaron/bipolaron, bond-order wave, charge/spindensity wave, and Tomonaga-Luttinger liquid (non-Fermi liquid). In principal, 1D structures allow the formation of various kinds of ordered phases, which sometimes break the translational symmetry of lattice, charge, or spin degrees of freedom. Although quantum fluctuations, which play a prominent role in 1D systems, suppress long-range ordering at finite temperatures, transverse interactions, which are usually present in actual systems, lead to an ordered state. Because anisotropic $\mathrm{p}$ and $\mathrm{d}$ orbitals of components as well as directiona interactions, such as hydrogen and $\pi-\pi$ interactions, between components are dominant factors in determining the anisotropic packing motif in metal-complex and molecular solids, it is apparent that these compounds are a promising platform for investigating low-dimensional electronic systems showing phase transitions as a function of temperature and pressure. In fact, the first spin-Peierls transition, which has been predicted to occur in certain compounds composed of spin-1/2 antiferromagnetic chains, was found in a molecular solid, TTF.Cu(tfd $)_{2} \quad$ (TTF: tetrathiafulvalene, tfd: 1,2 bis(trifluoromethyl)ethene-1,2-dithiolate), in $1975,{ }^{4}$ more than a decade prior to the first discovery of an inorganic spin-Peierls compound, $\mathrm{CuGeO}_{3} .^{5}$

In 1D metal complexes, an axial overlapping of the $d_{z}^{2}$ orbitals of group 10 metals, such as $\mathrm{Ni}, \mathrm{Pd}$, and $\mathrm{Pt}$, is indispensable for securing conduction pathways. A representative example is prototype Krogmann's salt, $\mathrm{K}_{2} \mathrm{Pt}(\mathrm{CN})_{4} \mathrm{Br}_{0.3} \cdot 3 \mathrm{H}_{2} \mathrm{O}$ (so-called $\mathrm{KCP}(\mathrm{Br})),{ }^{6}$ which involves a 1D chain comprising square-planar $\mathrm{PtCl}_{4}$ subunits arranged through $\mathrm{Pt}$...Pt interactions. A marked overlap between the $5 \mathrm{~d}_{\mathrm{z}}{ }^{2}$ orbitals of $\mathrm{Pt}$ results in band formation, and 0.3 holes per $\mathrm{Pt}$ (i.e., $\mathrm{Pt}^{2.3+}$ ) serve as carriers in the solid with a partially filled band. In 1974, it was found that this complex behaves as metallic above approximately $250 \mathrm{~K},{ }^{7}$ below which the conductivity becomes thermally activated due to Peierls instability arising from the electron-phonon interactions in the 1D system. On the other hand, in molecular solids, such as that comprising electron-donating TTF and electron-accepting 7,7,8,8-tetracyano- $p$-quinodimethane (TCNQ) discovered independently by two groups in $1973,8,9$ each component constructs a $\pi$-stacking column through $\pi$ orbital overlap, and the inter-column charge transfer (CT) interactions between TTF and TCNQ cause the generation of carriers within both columns. TTF.TCNQ with a partial CT (0.59) is currently regarded as the first molecular or synthetic metal and also shows complicated phase transitions associated with the Peierls instabilities at low temperatures. ${ }^{10}$ In both systems, itineracy depends largely on the balance between transfer energy ( $t \approx W / 4$ in $1 D$ electronic systems; $W$ : bandwidth), on- or inter-site Coulomb repulsion energy ( $U$ or $V$, respectively), and site-diagonal (or intra-site) and site-off-diagonal (or inter-site) electron-phonon coupling energy $(S) .{ }^{11}$ This review covers recent developments in each system after providing a general introduction to some materials comprehensively discussed in earlier review articles ${ }^{1-3,12-14}$ and compares the electronic behavior of $1 \mathrm{D}$ metal-chain complexes and organic conductors to provide a deeper understanding of how molecular and crystal structures affect the electronic properties. We mainly focused

\footnotetext{
Division of Chemistry, Graduate School of Science, Kyoto University, 


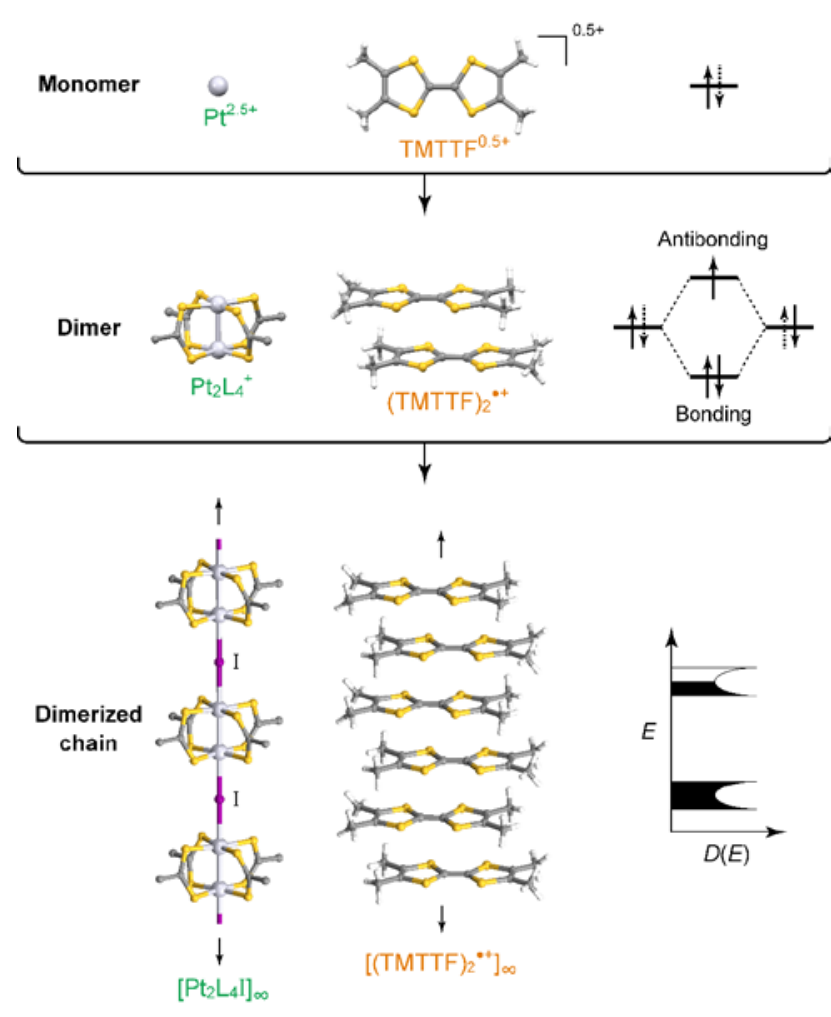

Fig. 1 Comparison of the monomeric, dimeric, and assembled structures of (left) $\mathrm{Pt}_{2} \mathrm{~L}_{4} \mathrm{l}\left(\mathrm{L}=\mathrm{RCS}_{2}{ }^{-}\right)$and (right) (TMTTF) $)_{2} \mathrm{X}$ (X: monoanion) together with their electronic states $(D(E)$ : density of states).

on neutral MMX-chain complexes, in which binuclear metal subunits $(\mathrm{MM})$ are connected by a halogen $(X)$, and cation radical salts, $(\text { TMTTF })_{2} X$ (TMTTF: tetramethyl-TTF, $X$ : monoanion), in which cationic TMTTF ${ }^{0.5+}$ molecules form a weakly dimerized $\pi$-stacking column, as examples of 1D metalcomplex and molecular solids, respectively (Fig. 1), because both systems are increasingly recognized to be full of examples of the relevance of electronic behavior to lattice, charge, and spin degrees of freedom.

\section{MMX-Chain Complex Family}

The first halogen-bridged $\mathrm{MX}$-chain complex, in which metal (M) and halogen (X) species are arranged in an alternating manner through the antibonding combination of $M\left(d_{z}{ }^{2}\right)$ and $X\left(p_{z}\right)$ orbitals, was synthesized by Wolfram more than a century ago. ${ }^{15}$ In $\left[\mathrm{Pt}\left(\mathrm{EtNH}_{2}\right)_{4} \mathrm{Cl}_{\mathrm{Cl}} \mathrm{Cl}_{2} \cdot 2 \mathrm{H}_{2} \mathrm{O}\right.$, the so-called Wolfram's red salt, mixed valence $\mathrm{Pt}^{2+}\left(\mathrm{d}^{8}\right)$ and $\mathrm{Pt}^{4+}\left(\mathrm{d}^{6}\right)$ ions are arranged alternately primarily due to the significant site-diagonal electron-phonon interactions $\left(U<S\right.$; negative- $U$ effect; ${ }^{16}$ Fig. 2(a)). ${ }^{17}$ Such a mixed valence state is accompanied by opening of the energy gap $(\Delta)$ resulting in nonmagnetic insulating behavior. Replacing Pt with a lighter homologous element, i.e. $\mathrm{Ni}$, provides an averaged valence state of +3 , in which the unpaired electron is localized due to the on-site Coulomb interactions $(U>W$; Fig. 2(b)) while maintaining a spin degree of freedom. Regardless of their origin, all the MX-chain complexes reported to date show insulating behavior. Instead, the efforts in synthesizing chain complexes based on binuclear metal subunits (MMs) have been devoted to exploring diverse electronic states mainly because of the reduced electronelectron correlations. In MMX-chain complexes, a halogen (X) serves as a bridge between MMs, each of which is assembled by four bidentate ligands in a paddle-wheel fashion. In a PtPt subunit, the $\mathrm{Pt}^{2+}\left(\mathrm{d}^{8}\right)$ ions adopt a planar four-coordinate geometry with no $\mathrm{Pt}^{2+}-\mathrm{Pt}^{2+}$ bond within the subunit, whereas $\mathrm{Pt}^{3+}\left(\mathrm{d}^{7}\right)$ ions adopt an octahedral coordination geometry to form an intra-subunit $\mathrm{Pt}^{3+}-\mathrm{Pt}^{3+}$ bond. ${ }^{12,18}$ Therefore, each $\mathrm{Pt}^{3+}$ ion can form a covalent bond with a bridging iodine, i.e., the iodine is displaced from the central position between two adjacent subunits depending on the valence state and approaches closer to $\mathrm{Pt}^{3+}$. As shown in Fig. 3, four types of valence states appear in the MMX chain depending primarily on the valence states of Pt ions: (a) averaged-valence (AV) state: uniform chain composed of $\mathrm{Pt}^{2.5+}-\mathrm{Pt}^{2.5+}$ homovalent dimers, showing metallic $(U<W)$ or Mott insulating $(U>W)$ behavior; (b) charge-density wave (CDW) state: alternating chain comprising $\mathrm{Pt}^{2+}-\mathrm{Pt}^{2+}$ and $\mathrm{Pt}^{3+}-\mathrm{Pt}^{3+}$ homovalent dimers; (c) charge-polarization (CP) state: uniform chain composed of $\mathrm{Pt}^{2+}$ $\mathrm{Pt}^{3+}$ heterovalent dimers with a parallel orientation; (d) alternate charge-polarization (ACP) state: alternating chain comprising $\mathrm{Pt}^{2+}-\mathrm{Pt}^{3+}$ heterovalent dimers with an antiparallel orientation. It should be noted that the valence states $\mathrm{Pt}^{2+}$ and $\mathrm{Pt}^{3+}$ are more accurately represented by $\mathrm{Pt}^{(2+\delta)+}$ and $\mathrm{Pt}^{(3-\delta)+}$, respectively, where the $\delta$ value $(0<\delta<0.5)$ significantly depends on the degree of orbital hybridization. The CP state retains the periodicity of the original AV state, whereas the CDW and ACP states described as Peierls and spin-Peierls states, respectively, deform their chain structures to produce a doubled periodicity as -Pt-Pt-I-Pt-Pt-I-. The spin degree of freedom, which is maintained in the $A V$ and CP states, is essentially frozen in the CDW and ACP states in the extreme case $(\delta=0)$ due to the opening of the spin gap. The CP state with

(a) $\mathrm{M}=\mathrm{Pd}$ or Pt $(U<0)$

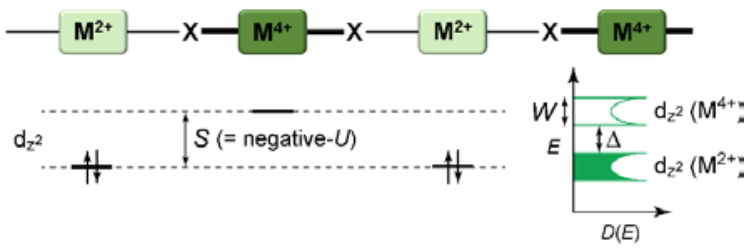

(b) $\mathrm{M}=\mathrm{Ni}(U>\mathrm{W}$

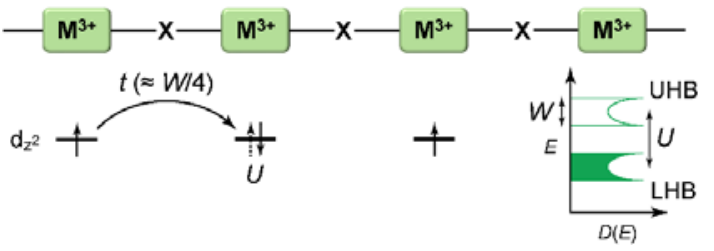

Fig. 2 Schematic electronic structures of (a) mixed-valence $(M=P d$ or $P t)$ and (b) Mott-Hubbard ( $\mathrm{M}=\mathrm{Ni}$ ) insulating states in $\mathrm{MX}$-chain complexes (UHB: upper Hubbard band, LHB: lower Hubbard band) related to physical parameters such as on-site Coulomb repulsion energy $(U)$, bandwidth $(W)$ or transfer energy ( $t \approx W / 4$ in 1D electronic systems), and electron-phonon coupling energy $(S) .{ }^{18,25} S$ is proportional to a spatial distortion from the equilibrium structure with a coefficient $B$ (i.e., site-diagonal electronphonon coupling constant), whereas $t$ becomes smaller in proportional to the spatial distortion with a coefficient $\alpha$ (i.e., site-off-diagonal electronphonon coupling constant). ${ }^{27,28,30}$ 
(a) Averaged-valence (AV) state

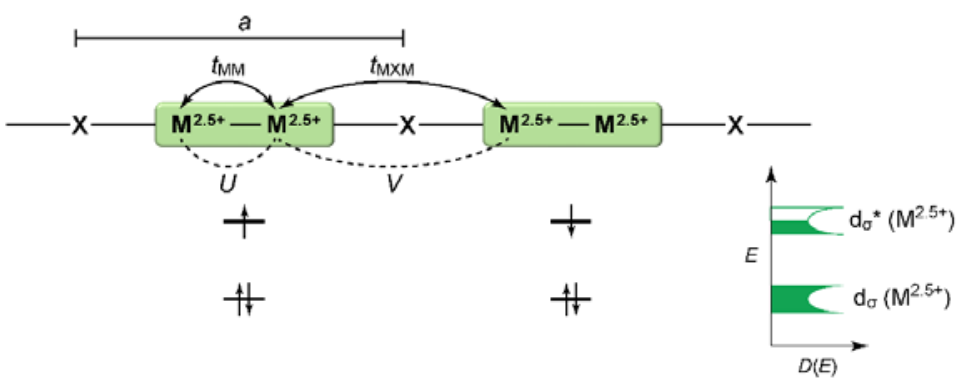

(b) Charge-density wave (CDW) state

$U<W\left(\approx 4 t_{M \times M}\right)$

$2 a$

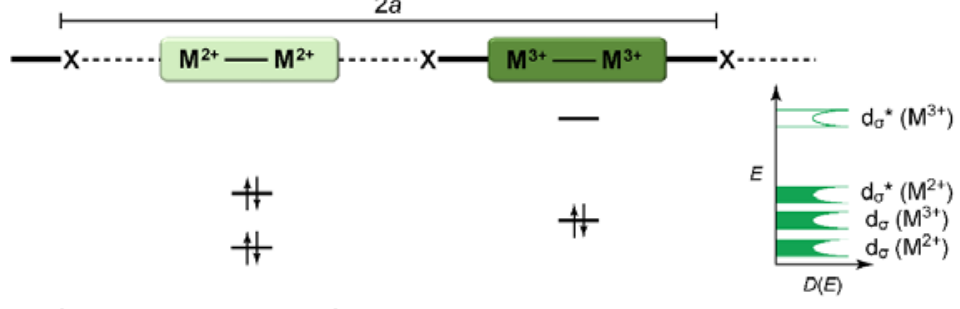

(c) Charge-polarization (CP) state

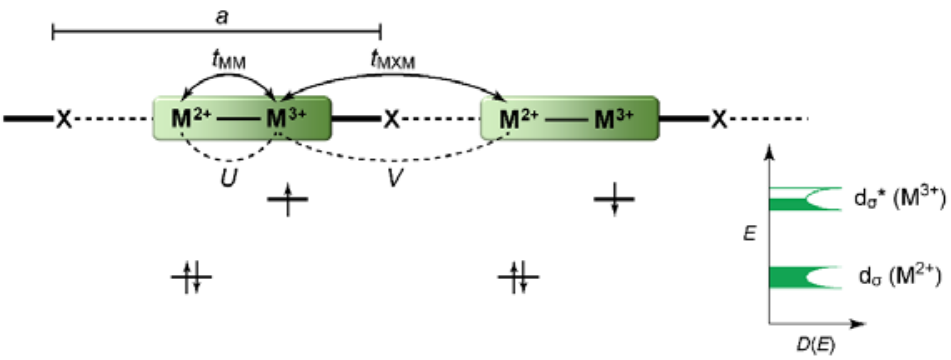

(d) Alternate charge-polarization (ACP) state

$2 a$

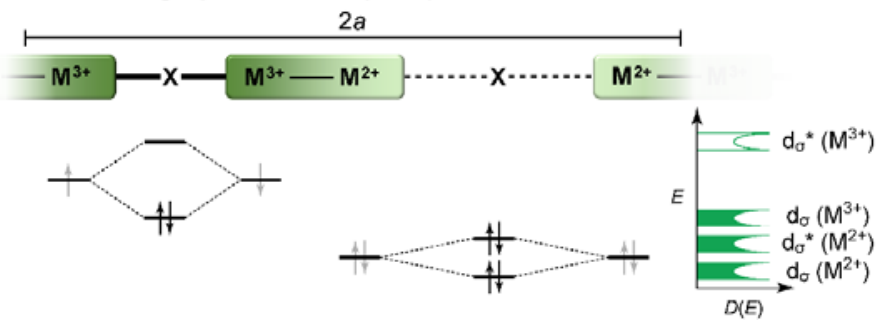

Fig. 3 Schematic electronic structures of the typical states in MMX-chain complexes: (a) averaged-valence (AV) state, (b) charge-density wave (CDW) state, (c) charge-polarization (CP) state, and (d) alternate chargepolarization (ACP) state ( $a$ : periodicity of an $-\mathrm{M}-\mathrm{M}-\mathrm{I}-$ unit, $t_{\mathrm{MM}}$ : transfer energy within an $\mathrm{MM}$ subunit, $t_{\mathrm{M} \times \mathrm{M}}$ : transfer energy between the subunits, $V$ : inter-site Coulomb repulsion energy). ${ }^{18}$

a permanent dipole moment has the potential to show ferroelectric behavior at a glance. In actual solids, these chains interact only weakly with each other through van der Waals forces, thereby identifying with a 1D electronic system.

The first MMX-chain complex, $\mathrm{Pt}_{2}\left(\mathrm{MeCS}_{2}\right)_{4}$ l, was synthesized by Bellitto et al. in $1983 .{ }^{19}$ In this solid, four bidentate dithiocarboxylate ligands ( $\mathrm{RCS}_{2}{ }^{-} ; \mathrm{R}$ : alkyl group) are attached to two Pt ions in a square planar coordination for each $\mathrm{Pt}$, and the paddle-wheel-shaped building units are assembled in a linear fashion by the bridging iodines. It is apparent that the ligands are responsible for the spatial isolation of the chains from each other, producing a 1D electronic state. To date, several MMXchain complexes have been synthesized using $\mathrm{RCS}_{2}{ }^{-}$ligands with different alkyl chain lengths. Another extensively studied line of research is $\left.\mathrm{A}_{4}\left[\mathrm{Pt}_{2} \text { (pop) }\right)_{4} \mathrm{I}\right] \cdot n \mathrm{H}_{2} \mathrm{O}$ (A: monocation, pop: $\mathrm{P}_{2} \mathrm{H}_{2} \mathrm{O}_{5}{ }^{2-}$ ),

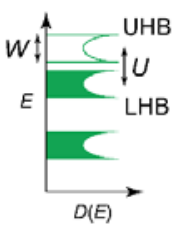

which is already the subject of some reviews ${ }^{12,20,21}$ and therefore will not be dealt with here. Typically, $\mathrm{Pt}_{2}\left(\mathrm{RCS}_{2}\right)_{4} \mathrm{l}$ can be prepared by the thermal treatment of a $\mathrm{Pt}^{2+}$ dimer complex, $\mathrm{Pt}_{2}\left(\mathrm{RCS}_{2}\right)_{4}$, and a $\mathrm{Pt}^{3+}$ dimer complex, $\mathrm{Pt}_{2}\left(\mathrm{RCS}_{2}\right)_{4} \mathrm{I}_{2}$, in toluene or toluene/hexane solution, where the acidic ligands $\mathrm{RCS}_{2} \mathrm{H}$ are commonly synthesized by the reaction of appropriate alkyl Grignard reagents with carbon disulfide in tetrahydrofuran/diethyl ether solution at low temperatures. ${ }^{22}$ It is well-known that $\mathrm{Pt}_{2}\left(\mathrm{MeCS}_{2}\right)_{4} I$ with $\mathrm{R}=$ Me can also be prepared by the iodine oxidation of $\mathrm{Pt}_{2}\left(\mathrm{MeCS}_{2}\right)_{4}(\mathrm{Pt} / \mathrm{I}$ molar ratio of 2:1) in toluene solution. ${ }^{19}$

$\mathrm{Pt}_{2}\left(\mathrm{MeCS}_{2}\right)_{4} \mathrm{l}$ is not only the second example, after $\mathrm{KCP}(\mathrm{Br})$, of the transition-metal complex showing metallic behavior under ambient pressure but also the first example of metallic neutral chain complex. Its metallic behavior could be observed only when a highpurity single crystal was used for the transport measurements. ${ }^{23,24}$ At room temperature, the complex belongs to the monoclinic space group $C 2 / c$, and each infinite chain running along the $b$ axis includes one-Pt-Pt-I- unit in a unit cell (Fig. 4). $18,19,25$ Along the side-by-side direction $(/ / c)$, there are heteroatomic S...S contacts with a distance (ca. $3.8 \AA$ A) slightly longer than the sum of van der Waals radii (3.60 A). Provided that the intrasubunit transfer energy $\left(t_{\mathrm{MM}}\right)$ is comparable to the inter-subunit transfer energy $\left(t_{\mathrm{MXM}}\right)$, the $\mathrm{d}_{\mathrm{z}}{ }^{2}$ band is originally three-quarter-filled, $\left(5 d_{z}^{2}\right)^{2}\left(5 d_{z}^{2}\right)^{1}$. However, the possible condition $t_{\mathrm{MM}}>t_{\mathrm{MXM}}$ results in the splitting of $d_{z}{ }^{2}$ into bonding $d_{\sigma}$ and antibonding $d_{\sigma} *$ due to dimerization, latter of which is in the half-filled state (Fig. $3(a))$. It is noteworthy that contrary to the $d_{\sigma}$ orbital, the $d_{\sigma}{ }^{*}$ orbital possibly expands towards the outside of the subunit, which facilitates electron transfer between the subunits (i.e., $\left.t_{\mathrm{MXM}}\right)$. The conductivity of $\mathrm{Pt}_{2}\left(\mathrm{MeCS}_{2}\right)_{4} l$ along the chain direction is ca. $13 \mathrm{~S} \mathrm{~cm}^{-1}$ at room temperature and shows metallic behavior above approximately $300 \mathrm{~K}$ (Fig. 5(a)). A temperatureindependent thermoelectric power above room temperature strongly suggests that the complex has a half-filled metallic state in this temperature range. The observation of a single $C=S$ stretching band in the infrared (IR) spectra is firm evidence for the formation of the AV state. The insulating phase caused by a metal-insulator transition can be readily assigned to the $C P$ state (Fig. 3(c)) because of its significant magnetic susceptibility 
(Fig. 5(b)) as well as the splitting of the $\mathrm{C}=\mathrm{S}$ stretching mode (trapped-valence states $\mathrm{Pt}^{2+}$ and $\mathrm{Pt}^{3+}$ ). The ${ }^{129}$ Mössbauer spectra showing two different iodine sites below $80 \mathrm{~K}$ indicate that the electronic state formed below $80 \mathrm{~K}$ is the ACP state (Fig. $3(d))$, which is consistent with that predicted by theoretical studies. ${ }^{26-28}$ Because it is reasonable to expect that the Pt-I bonds are more compressible than the Pt-Pt bonds in $\mathrm{MMX}$ chains, the $t_{\mathrm{MXM}}$ approaches the $t_{\mathrm{MM}}$ as the temperature is decreased. Thus, the degree of dimerization in the MMX-chain (i.e., difference between $t_{\mathrm{MM}}$ and $t_{\mathrm{MXM}}$ ) weakens upon cooling, which could have a favorable effect on the stability of a chargeordered (CO) state as compared to that on a dimer-Mott state. ${ }^{29}$ Although the increase in $V$ owing to lattice compression must stabilize the CP state, the emergence of the ACP state at lower temperatures might be associated with the magnetic energy gain due to the opening of the spin gap. In this regard, site-off-

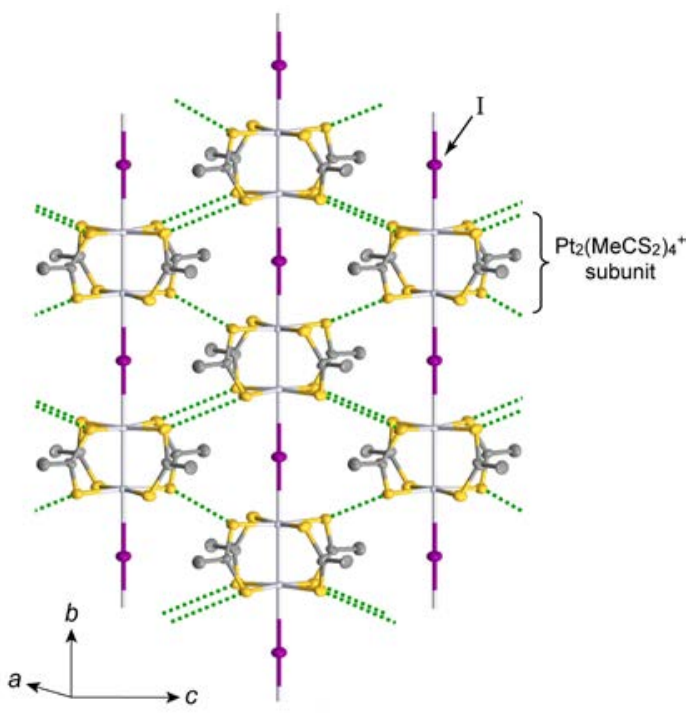

Fig. 4 Crystal structure of $\mathrm{Pt}_{2}\left(\mathrm{MeCS}_{2}\right)_{4} \mathrm{l}$ at room temperature, ${ }^{18,19}$ where green dotted lines show heteroatomic S $\cdots S$ contacts between adjacent chains. Hydrogen atoms are omitted for clarity.
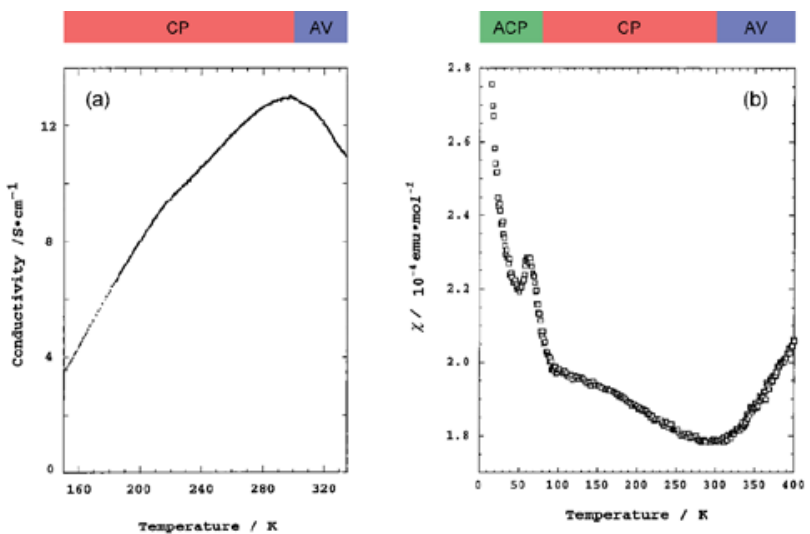

Fig. 5 Temperature dependence of (a) conductivity and (b) magnetic susceptibility $(\chi)$ of $\mathrm{Pt}_{2}\left(\mathrm{MeCS}_{2}\right)_{4} \mathrm{l}$ (AV: averaged-valence state, $\mathrm{CP}$ : chargepolarization state, ACP: alternate charge-polarization state). Adapted with permission from ref. 18. Copyright 1999 American Chemical Society. diagonal electron-phonon interactions that modulate the transfer energies, especially $t_{\mathrm{MXM}}$ in this system, must be beneficial for realizing an ACP state with redistributed tetramers. ${ }^{27,30}$

$\mathrm{Pt}_{2}\left(\mathrm{EtCS}_{2}\right)_{4} \mathrm{l}$ (space group: $\mathrm{C2} / \mathrm{c}$ ), in which the methyl groups of ligands in $\mathrm{Pt}_{2}\left(\mathrm{MeCS}_{2}\right)_{4}$ l are replaced with longer ethyl groups, was synthesized by Mitsumi et al. via the reaction of $\mathrm{Pt}_{2}\left(\mathrm{EtCS}_{2}\right)_{4}$ with $\mathrm{Pt}_{2}\left(\mathrm{EtCS}_{2}\right)_{4} \mathrm{I}_{2}$ in toluene. ${ }^{31}$ The complex shows a roomtemperature conductivity of 5-30 $\mathrm{S} \mathrm{cm}^{-1}$, comparable to that of $\mathrm{Pt}_{2}\left(\mathrm{MeCS}_{2}\right)_{4} \mathrm{l}$, and a conductivity maximum at $205 \mathrm{~K}$. Because the X-ray diffuse scattering lines corresponding to the 2 -fold periodicity along the chain direction start to grow below $160 \mathrm{~K}$, it is likely that the conductivity change at $205 \mathrm{~K}$ occurs due to a phase transition from the metallic AV to the Mott-insulating AV or charge-ordered CP state (Raman spectra suggest the coexistence of these states $\left.{ }^{32}\right)$. X-ray structural refinement revealed that the low-temperature phase $(<160 \mathrm{~K})$ with a 2 -fold $-\mathrm{Pt}-\mathrm{Pt}-\mathrm{I}-$ unit repetition is identical to the ACP state, i.e., $-\mathrm{Pt}^{2+}-$ $\mathrm{Pt}^{3+}-1-\mathrm{Pt}^{3+}-\mathrm{Pt}^{2+}-\mathrm{I}-$ (space group: $\left.P-1\right) .^{33}$ The emergence of the ACP state was confirmed by ${ }^{129}$ I Mössbauer spectroscopy, which estimates the charge of iodine bridging the $\mathrm{Pt}^{3+}$ ions to be -0.4 and that of iodine bridging the $\mathrm{Pt}^{2+}$ ions to be $-0.3 .^{34}$ This structural feature is seemingly inconsistent with the magnetic susceptibility data, which indicate the presence of the spin degree of freedom even below $160 \mathrm{~K}$ (Fig. 6). This discrepancy can probably be explained by the difference between the degrees of lattice deformation within the chain. In fact, the difference between the $\mathrm{Pt}^{2+}-\mathrm{I}$ and $\mathrm{Pt}^{3+}-\mathrm{I}$ bond lengths $(0.02-$ $0.03 \AA)$ is significantly smaller than that in the case of $\operatorname{Pt}_{2}(n-$ $\left.\mathrm{BuCS}_{2}\right)_{4}$ l (ca. $0.07 \AA$ ) $), 33$ which shows a rapid drop in magnetic susceptibility associated with the first-order transition, as expected from the ideal ACP state (Fig. 6). As above-mentioned, the observation of ferroelectric behavior in the CP state is of fascinating interest. The distorted ESR spectra shown in Fig. 7 is indicative of the significantly reduced cavity quality factor, which is inversely proportional to dielectric loss, $\tan \delta$, possibly due to the emergence of ferroelectricity. ${ }^{35}$ The temperature range of the distorted spectra $(130-140 \mathrm{~K})$ is below the transition temperature at which the superstructure associated

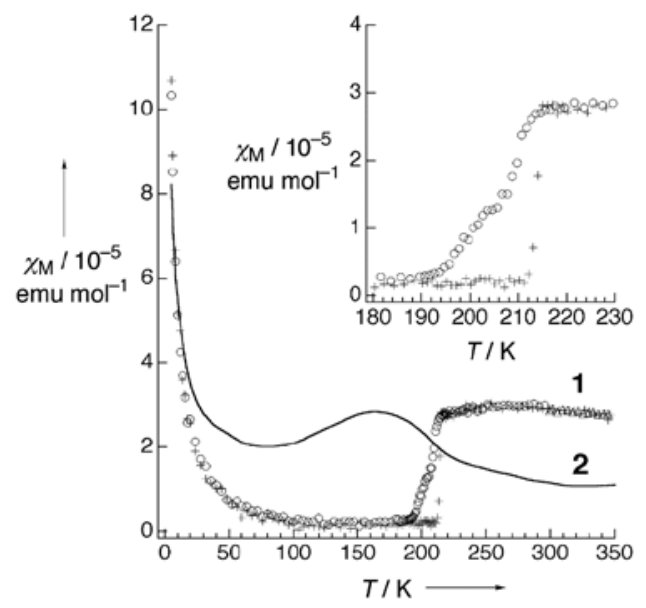

Fig. 6 Temperature dependence of magnetic susceptibility $\left(\chi_{\mathrm{M}}\right)$ of $\mathrm{Pt}_{2}\left(\mathrm{EtCS}_{2}\right)_{4} \mathrm{l}(2)$ and $\mathrm{Pt}_{2}\left(n-\mathrm{BuCS}_{2}\right)_{4} \mathrm{l}$ (1; o: 1st cooling, +: 1st heating, $\Delta$ : 2nd cooling). Inset shows the phase transition behavior at around $210 \mathrm{~K}$ of 1 . Adapted with permission from ref. 33. Copyright 2002 Wiley-VCH. 


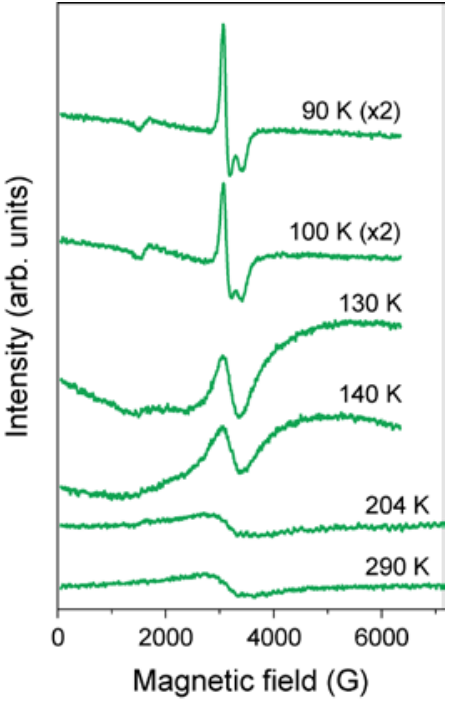

Fig. 7 Temperature dependence of ESR spectra of polycrystalline $\mathrm{Pt}_{2}\left(\mathrm{EtCS}_{2}\right)_{4} \mathrm{l}^{35}$

with the ACP state starts to grow $(160 \mathrm{~K})$ because of the gradual growth of the ACP state.

Pressure has been applied to not only search the unexplored electronic states, but also control the electronic properties. As shown in Fig. 8, the room-temperature resistivity of $\mathrm{Pt}_{2}\left(\mathrm{EtCS}_{2}\right)_{4} \mathrm{I}$ is steadily decreased upon applying hydrostatic pressure of up to $3 \mathrm{GPa}$ principally due to the increase in bandwidth caused by lattice compression. ${ }^{32,36}$ The conductivity maximum observed at $205 \mathrm{~K}$ under ambient pressure rapidly disappears when moderate pressure is applied and clearly revives under higher

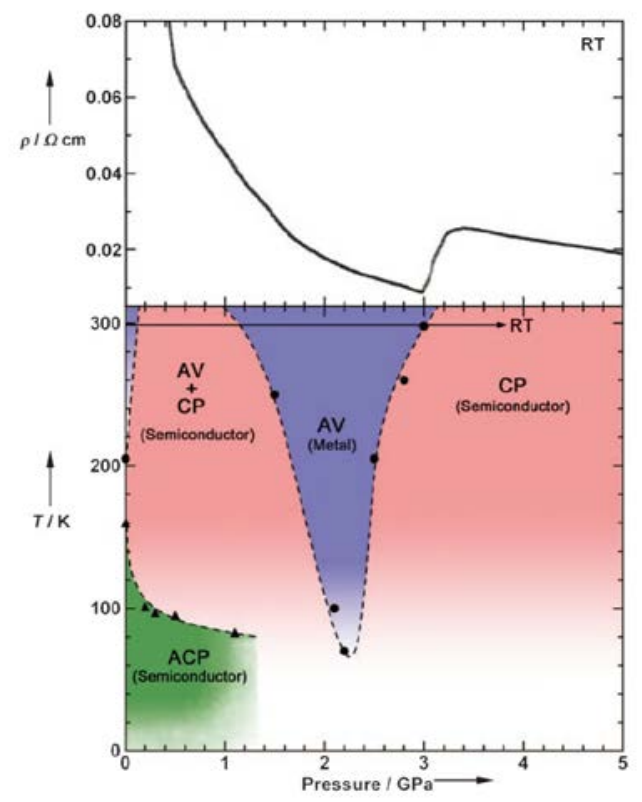

Fig. 8 (Upper) Pressure dependence of room-temperature resistivity $(\rho)$ and (lower) electronic $T-P$ phase diagram of $\mathrm{Pt}_{2}\left(\mathrm{EtCS}_{2}\right)_{4} \mathrm{l}$, where a panel presented in the original paper ${ }^{32}$ was omitted. Adapted with permission from ref. 32. Copyright 2009 Wiley-VCH. pressures (ca. $70 \mathrm{~K}$ at $2.2 \mathrm{GPa}$ ). Of particular importance is that the metallic behavior disappears again above this pressure and the conductivity shows thermally activated behavior. The insulating phase is readily assigned to the CP state based on the crystallographic and Raman studies as a function of pressure. Theoretical calculations predicted that the application of pressure leads to the stabilization of the reentrant CP state. ${ }^{27}$ The reason must be the same as above-mentioned for low temperatures: the increased $V$ relative to $t_{\mathrm{MM}}$ due to the shortened inter-subunit distance under pressure. Similar behavior of the stabilization of the $\mathrm{CP}$ state by applying pressure was observed for $\mathrm{Pt}_{2}\left(\mathrm{MeCS}_{2}\right)_{4} \mathrm{l}$ (Fig. 9). ${ }^{37}$ It is interesting to note that the proposed $T-P$ phase diagrams for $\mathrm{Pt}_{2}\left(\mathrm{RCS}_{2}\right)_{4}$ l are quite different from that of (TMTTF) ${ }_{2} X$ (see below), in which the pressure transforms the salts from 1D (Tomonaga-Luttinger liquid) to 3D (Fermi liquid) metals to stabilize the AV state. ${ }^{14,38,39}$ Although the factors that determine the electronic state under pressure remain unclear, the persistent 1D character of $\mathrm{Pt}_{2}\left(\mathrm{RCS}_{2}\right)_{4} \mathrm{l}$ due to the subtle interchain interactions may be a part of the reason.

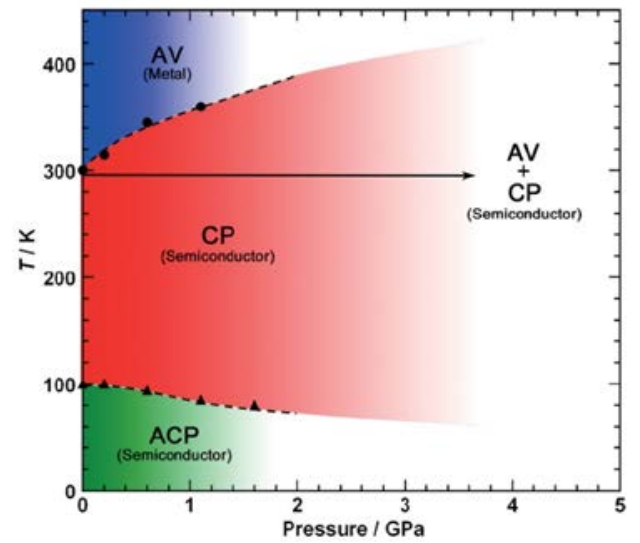

Fig. 9 Electronic $T-P$ phase diagram of $\mathrm{Pt}_{2}\left(\mathrm{MeCS}_{2}\right)_{4}$ l. Adapted with permission from ref. 37. Copyright 2016 Wiley-VCH.

A peculiar valence state was found for $\mathrm{Pt}_{2}\left(n-\mathrm{PenCS}_{2}\right)_{4} \mid$ with longer $n$-pentyl groups. It has a relatively low roomtemperature conductivity $\left(0.84 \mathrm{~S} \mathrm{~cm}^{-1}{ }^{40}\right)$ but retains metallic behavior down to $255-270 \mathrm{~K}^{41}$ or $235 \mathrm{~K} .{ }^{42}$ On further cooling, the complex shows an abrupt drop in conductivity at ca. $200 \mathrm{~K}^{41}$ or $205 \mathrm{~K}, 42$ which is close to a first-order transition temperature (207.4 K) observed for the heat capacity profile. ${ }^{40}$ At the same temperature, magnetic susceptibility rapidly vanishes with decreasing temperature possibly because of the transition from the paramagnetic (AV) to the nonmagnetic (CDW or ACP) state. To date, the valence state at low temperatures remains highly controversial due to the complicated X-ray diffuse scattering patterns possibly arising from valence fluctuations. ${ }^{41,42}$ However, it is most likely that the low-temperature phase involves a 3-fold -Pt-Pt-I- unit repetition as $-\mathrm{Pt}^{3+}-\mathrm{Pt}^{2+}-1-\mathrm{Pt}^{2+}-$ $\mathrm{Pt}^{3+}-1-\mathrm{Pt}^{2.5+}-\mathrm{Pt}^{2.5+}-\mathrm{I}-$, comprising alternating $\mathrm{ACP}$ and $\mathrm{AV}$ states. A similar sign of the 3-fold periodicity along the chain direction was found for $\left.\mathrm{Pt}_{2}\left(n-\mathrm{PrCS}_{2}\right)_{4}\right|^{43}$ and $\mathrm{Pt}_{2}\left(n-\mathrm{BuCS}_{2}\right)_{4} l^{33}$ Such an alternating chain composed of homovalent and heterovalent dimers has not been found in organic conductors, although there are $2 \mathrm{D}$ conducting layers comprising homovalent dimers 
with different charges (e.g., $k-(B E D T-T T F)_{4}\left(\mathrm{Et}_{4} \mathrm{~N}\right)\left[\mathrm{M}(\mathrm{CN})_{6}\right] \cdot n \mathrm{H}_{2} \mathrm{O}$ BEDT-TTF: bis(ethylenedithio)-TTF, $\mathrm{M}=\mathrm{Fe}^{3+}$ and $\mathrm{Co}^{3+} ; n=2^{44}$ and $3^{45}$ ) and uniform and alternately charged columns (e.g., $\alpha$ $\left.(\mathrm{BEDT}-\mathrm{TTF})_{2} \mathrm{l}_{3}{ }^{46}\right)$. The phase diagram of $\mathrm{Pt}_{2}\left(\mathrm{RCS}_{2}\right)_{4}$ l with different alkyl chain lengths is illustrated in Fig. 10.12,18,31-33,40-43,47-51

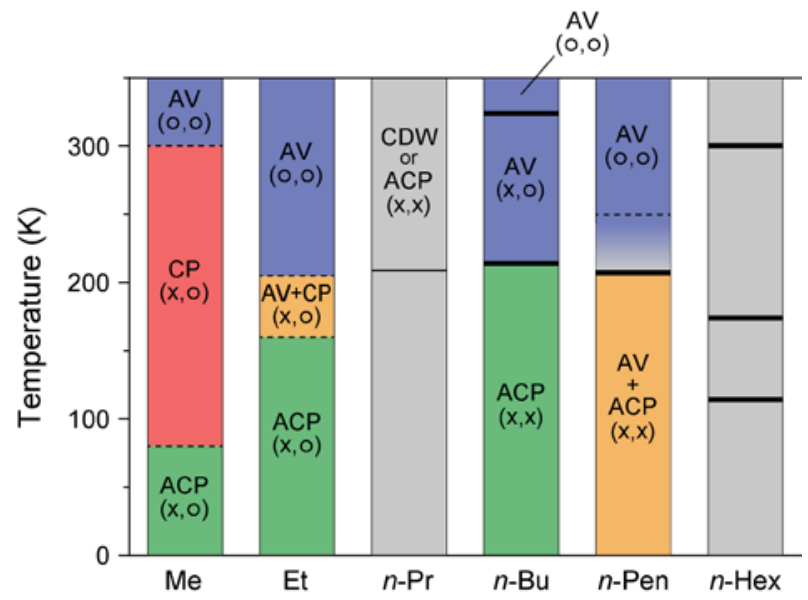

Fig. 10 Temperature dependence of the electronic states of $\mathrm{Pt}_{2}\left(\mathrm{RCS}_{2}\right)_{4} \mathrm{I}$ with different alkyl chain (R) lengths, where the superlattice structure is not considered. ${ }^{12,18,31-33,40-43,47-51}$ Gray areas show the temperature range whose electronic state is unknown, and symbols in parentheses indicate the charge (left) and spin (right) degrees of freedom. Thick and thin vertical lines indicate the first- and higher-order transition temperatures, respectively, observed by heat capacity measurements. ${ }^{40,48,49,51}$ For $\mathrm{R}=\mathrm{Me}$, no heatcapacity anomaly was observed at around 300 and $80 \mathrm{~K},{ }^{47}$ at which phase transitions occur between the $\mathrm{AV}$ and $\mathrm{CP}$ states and between the $\mathrm{CP}$ and $\mathrm{ACP}$ states, respectively. ${ }^{18}$ For $\mathrm{R}=\mathrm{Et}$, although numerical data of transition temperatures (ca. 180 and $230 \mathrm{~K}$ ) observed by the heat capacity measurements are presented in refs. 12 and 50, the source and full extent of the anomalies are not shown. For $\mathrm{R}=n$-Pen, no heat-capacity anomaly was observed at around $250 \mathrm{~K},{ }^{40}$ at which a conductivity maximum was observed during the resistivity measurements (shown by a dotted line). ${ }^{41,42}$

\section{3. (TMTTF) 2 X Family}

In the research of organic conductors, most of the interest in the chemistry field is focused on the synthesis of superconductors, which require increased electronic dimensionality to prevent the Peierls transition caused by the electron-phonon interactions in 1D systems. ${ }^{3,14}$ A good example is the BEDT-TTF cation radical salts mainly developed by Saito group ${ }^{52,53}$ and Williams and Schlueter group, ${ }^{54,55}$ which have provided a rich variety of $2 \mathrm{D}$ electronic materials with properties ranging from superconductors to quantum spin liquids. However, the collaborative efforts of chemists and physicists over the past decades have opened the possibility of applying (TMTTF) ${ }_{2} X$ to novel $1 \mathrm{D}$ physics owing to the various isostructural salts with electronic behavior sensitive to temperature and pressure.

In (TMTTF $)_{2} \mathrm{X},(\mathrm{TMTTF})_{2}{ }^{\bullet+}$ dimers with an $S=1 / 2$ spin connect to the adjacent dimers within the column mainly through the overlap of $\pi$-orbitals as compared to the overlap of $M\left(d_{z}{ }^{2}\right)-$ $\mathrm{M}\left(\mathrm{d}_{\mathrm{z}}{ }^{2}\right)$ orbitals through $\mathrm{X}\left(\mathrm{p}_{\mathrm{z}}\right)$ orbitals in $\mathrm{MMX}$-chain complexes. Herein, it is instructive to show how the columnar assembly in (TMTTF $)_{2} \mathrm{X}$ is compressed due to cooling relative to the case of an MMX-chain. ${ }^{56,57}$ As shown in Fig. 11(a), the heat shrinkage ratio of (TMTTF) ${ }_{2} \mathrm{PF}_{6}$ along the $\pi$-stacking column $(/ / a)$ is more than five times that of $\mathrm{Pt}_{2}\left(\mathrm{MeCS}_{2}\right)_{4} \mathrm{l}$ as a result of weak $\pi-\pi$ interactions between the TMTTF molecules. Similarly, the pressure dependence of relative lattice parameter along the chain direction with respect to that under ambient pressure is more significant in (TMTTF) ${ }_{2} \mathrm{PF}_{6}{ }^{58}$ than in $\mathrm{Pt}_{2}\left(\mathrm{MeCS}_{2}\right)_{4} \mathrm{l}$ (Fig. 11(b)). ${ }^{37}$ Such a structural feature facilitates the control of electronic behavior via temperature and chemical/physical pressure and therefore offers opportunities for experimental and theoretical works on the investigation of not only the quasi1D electronic states next to higher-dimensional electronic states, but also the dimensional crossover behavior between them. In this system, 3D ordered electronic states, such as antiferromagnetic ordered and superconducting states, appear at low temperatures under applied pressure.
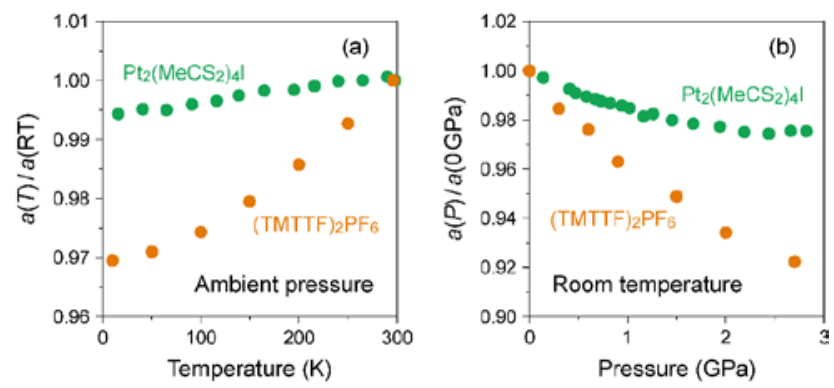

Fig. 11 (a) Temperature dependence of relative lattice parameters along the chain direction with respect to those at room temperature (RT) and (b) pressure dependence of relative lattice parameters along the chain direction with respect to those under ambient pressure for $\mathrm{Pt}_{2}\left(\mathrm{MeCS}_{2}\right)_{4}$ ( (green circles: data obtained from refs. 37 and 56) and (TMTTF) ${ }_{2} \mathrm{PF}_{6}$ (orange circles: data obtained from refs. 57 and 58).

TMTTF can be synthesized by the homocoupling of 1,3dithiolium salts, ${ }^{59-61}$ instead of 1,3-dithiol-2-one, -thione, or selone commonly used in the coupling reaction to produce TTF skeletons, under basic conditions (Fig. 12). Its purification can be achieved using recrystallization or sublimation methods. TMTTF has electron-donating ability (1st redox potential $E^{1} 1 / 2=$ $0.28 \mathrm{~V}$ vs. saturated calomel electrode (SCE)), and therefore, its cation radical salts can be readily prepared by electrooxidation in the presence of appropriate counter anions. ${ }^{3}$ Organic solvents such as 1,1,2-trichloroethane, acetonitrile, and

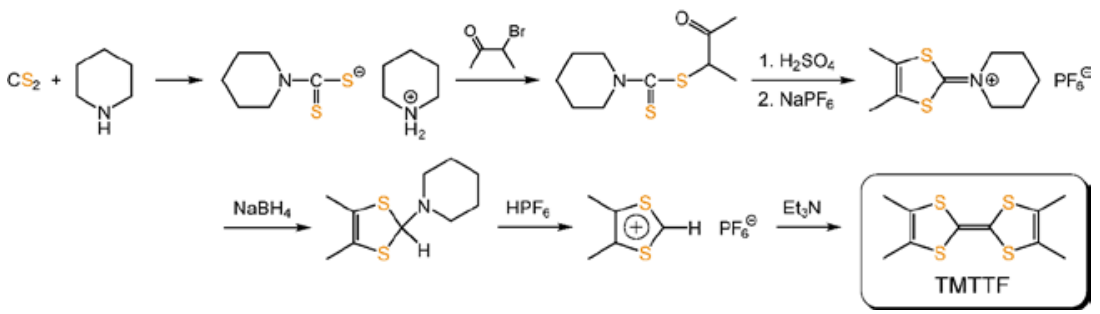

Fig. 12 An example of the synthetic scheme of TMTTF. ${ }^{61}$ 
tetrahydrofuran are commonly used as reaction solvents Chemical oxidation of TMTTF by acids ( $\mathrm{HX}: \mathrm{X}=\mathrm{BF}_{4}{ }^{-}$and $\left.\mathrm{ClO}_{4}{ }^{-}\right)$ and metathesis of (TMTTF) ${ }_{2} \mathrm{BF}_{4}$ with $\mathrm{AX}$ ( $\mathrm{A}$ : monocation; $\mathrm{X}=\mathrm{PF}_{6}{ }^{-}$, $\mathrm{SCN}^{-}$, and $\mathrm{Br}^{-}$) are also employed for synthesizing the (TMTTF) $)_{2} \mathrm{X}$ salts. ${ }^{62}$

Since the first synthesis of (TMTTF) ${ }_{2} X$ salts in 1977,63 various isostructural salts have been obtained by combining TMTTF with monoanions having octahedral (e.g., $\mathrm{PF}_{6}{ }^{-}, \mathrm{AsF}_{6}{ }^{-}$, and $\mathrm{SbF}_{6}{ }^{-}$), tetrahedral (e.g., $\mathrm{BF}_{4}^{-}, \mathrm{ClO}_{4}^{-}$, and $\mathrm{ReO}_{4}^{-}$), linear $\left(\mathrm{SCN}^{-}\right)$, or monoatomic $\left(\mathrm{Br}^{-}\right)$geometries. Whereas selenium analogues, i.e. (TMTSF $)_{2} \mathrm{X}$ salts, have served as an excellent model for quasi-1D superconductors, ${ }^{13}$ originated with the first organic superconductor, $\left(\mathrm{TMTSF}_{2} \mathrm{PF}_{6}\left(T_{\mathrm{c}}=0.9 \mathrm{~K}\right.\right.$ under $\left.1.2 \mathrm{GPa}\right)$, discovered by Jérome, Bechgaard, and coworkers in $1980^{64}$ followed by the $\mathrm{ClO}_{4}$ salt $\left(T_{\mathrm{c}}=1.4 \mathrm{~K}\right.$ under ambient pressure), ${ }^{65}$ the (TMTTF $)_{2} \mathrm{X}$ salts with a very rich phase diagram (Fig. 13) $)^{39,66}$ have provided an important clue for exploring the phenomena

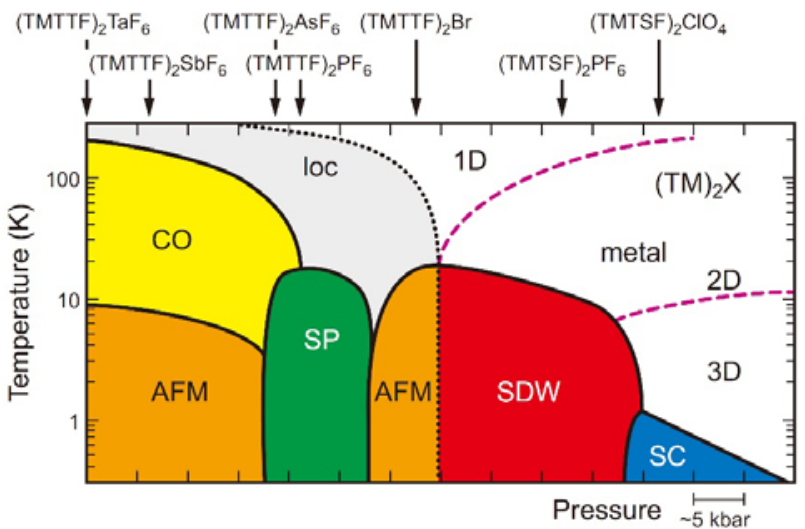

Fig. 13 Electronic $T-P$ phase diagram of (TMTTF) ${ }_{2} \mathrm{X}$ and (TMTSF) ${ }_{2} \mathrm{X},{ }^{66}$ in which the ordered states are drawn in colors (loc: Mott insulating state (localization), CO: charge-ordered state, AFM: antiferromagnetic ordered state, SP: spin-Peierls state, SDW: spin-density wave state, SC: superconducting state). Purple dashed lines indicate the dimensional crossover, whereas a black dotted line indicates a metal-insulator transition (see text for details). It is possible that $\mathrm{Pt}_{2}\left(\mathrm{RCS}_{2}\right)_{4}$ I with strong $1 \mathrm{D}$ character move toward the lower left direction instead of toward the beneath direction on a left side in this diagram.

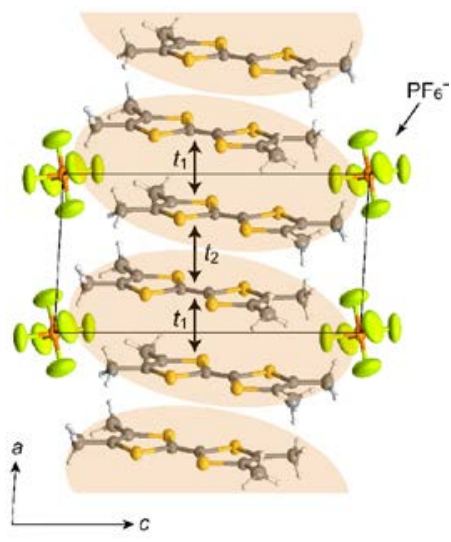

Fig. 14 Crystal structure of (TMTTF) ${ }_{2} \mathrm{PF}_{6}$ at room temperature viewed along the $b$ axis, where the TMTTF dimers are indicated by orange ellipses. $t_{1}$ and $t_{2}$ are intra- and inter-dimer transfer energies, respectively. of 1D physics. A point of interest is that the $1 \mathrm{D}$ electronic system cannot be simply described by the Fermi liquid picture with quasiparticle dispersions, which is commonly used to describe conventional metals and semiconductors. As mentioned below, the transport properties can be described in terms of the Tomonaga-Luttinger liquid theory, which shows peculiar spincharge separations and interactions due to independent spin and charge excitations with different velocities. ${ }^{67}$

In (TMTTF) $)_{2}$ (space group: $P$-1), the TMTTF molecules with an average charge of +0.5 weakly dimerize in a face-to-face fashion, and the TMTTF dimers with an $S=1 / 2$ spin assemble in a stacking manner via $\pi-\pi$ interactions along the $a$ axis (Fig. 14). The zig-zag arrangement is attributed to the steric hindrance of counter anions. For (TMTTF $)_{2} \mathrm{PF}_{6}$, the intradimer $\left(t_{1}\right)$ and interdimer $\left(t_{2}\right)$ transfer energies at room temperature were estimated to be 230.6 and $170.2 \mathrm{meV}$, respectively, whereas the inter-column transfer energies are small but substantial $(|t|<$ $25.2 \mathrm{meV})$. Theoretical calculation using the crystallographic

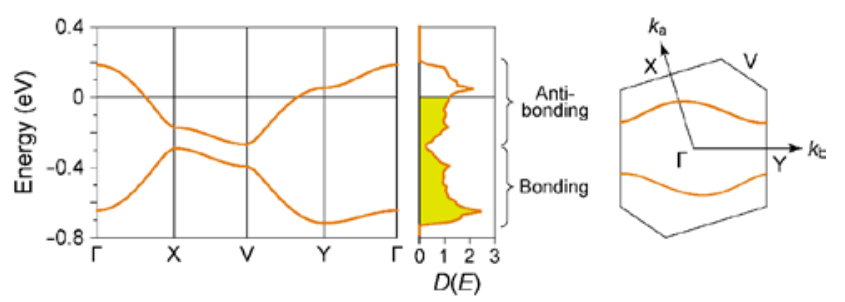

Fig. 15 Electronic band dispersions, densities of states $(D(E)$ in states per electronvolt per spin), and Fermi surfaces of (TMTTF) ${ }_{2} \mathrm{PF}_{6}$, calculated on the basis of the extended Hückel method with the tight-binding approximation using crystallographic data at room temperature. The energy is provided relative to the Fermi energy. Note that the electron-electron correlation is not considered in this calculation.

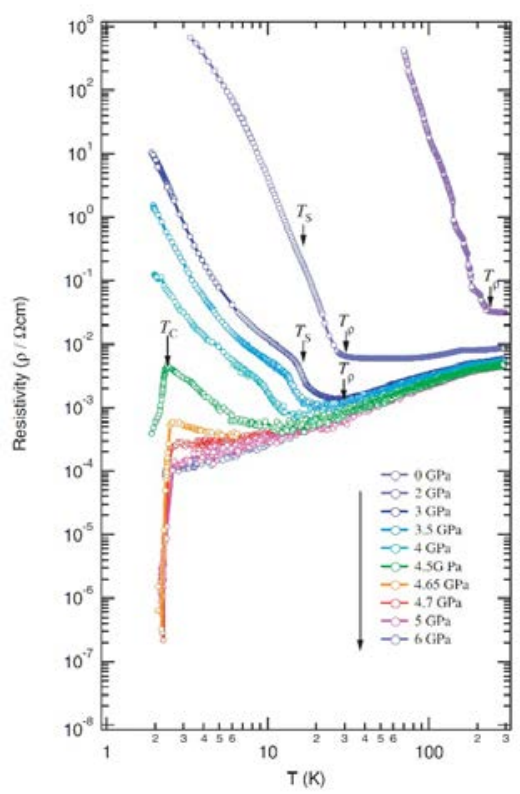

Fig. 16 Temperature dependence of resistivity of (TMTTF) ${ }_{2} \mathrm{AsF}_{6}$ under various pressures, where $T_{\rho}, T_{\mathrm{s}}$, and $T_{\mathrm{c}}$ are temperatures at minimum resistivity, spin-Peierls transition, and superconducting transition, respectively. Adapted with permission from ref. 72. Copyright 2007 Physical Society of Japan. 
Table 1 Properties of typical (TMTTF) ${ }_{2} \mathrm{X}^{\mathrm{a}}$

\begin{tabular}{lllllllll}
\hline $\mathrm{X}$ & $V_{\mathrm{a}}\left(\AA^{3}\right)$ & $T_{\sigma}(\mathrm{K})$ & $T_{\mathrm{CO}}(\mathrm{K})$ & $T_{\mathrm{AO}}(\mathrm{K})$ & $\mathrm{GS}$ & $P_{\mathrm{c}}(\mathrm{GPa})$ & $T_{\mathrm{c}}(\mathrm{K})$ & ref. $^{\mathrm{b}}$ \\
\hline $\mathrm{PF}_{6}{ }^{-}$ & 109 & 245 & $67[\mathrm{CP}]$ & & $\mathrm{SP}[15 \mathrm{~K}]$ & 5.2 & 1.8 & 70,71 \\
$\mathrm{AsF}_{6}{ }^{-}$ & 110 & 105 & $102[\mathrm{CP}]$ & & $\mathrm{SP}[13 \mathrm{~K}]$ & 4.5 & 2.4 & 72 \\
$\mathrm{SbF}_{6}{ }^{-}$ & 121 & 154 & $157[\mathrm{CP}]$ & & $\mathrm{AF}[8 \mathrm{~K}]$ & 5.4 & 2.8 & 73 \\
$\mathrm{TaF}_{6}{ }^{-}$ & 128 & $-{ }^{\mathrm{c}}$ & $177[\mathrm{CP}]$ & & $\mathrm{AF}[9 \mathrm{~K}]$ & $-{ }^{d}$ & $-{ }^{d}$ & \\
$\mathrm{BF}_{4}{ }^{-}$ & 73 & 190 & $84[\mathrm{ACP}]$ & 41 & $\mathrm{SS}[41 \mathrm{~K}]$ & 3.4 & 1.4 & 74 \\
$\mathrm{ClO}_{4}{ }^{-}$ & 82 & 230 & $-{ }^{d}$ & 73 & $\mathrm{AF}[12 \mathrm{~K}]$ & $-{ }^{d}$ & $-{ }^{d}$ & \\
$\mathrm{ReO}_{4}^{-}$ & 86 & 230 & $230[\mathrm{ACP}]$ & 157 & $\mathrm{SS}[157 \mathrm{~K}]$ & $-{ }^{d}$ & $-{ }^{d}$ & \\
$\mathrm{SCN}^{-}$ & 71 & 240 & $160[\mathrm{CP}]$ & 160 & $\mathrm{AF}[7 \mathrm{~K}]$ & $-{ }^{d}$ & $-{ }^{d}$ & \\
$\mathrm{Br}^{-}$ & 56 & 100 & $20[\mathrm{CP}]$ & & AF [15 K] & 2.6 & 0.8 & 75 \\
\hline
\end{tabular}

a $V_{\mathrm{a}}$ : anion volume (H. D. B. Jenkins, H. K. Roobottom, J. Passmor and L. Glasser, Inorg. Chem., 1999, 38, 3609) $T_{\sigma}$ : temperature at maximum conductivity; $T_{\mathrm{CO}}$ : charge-ordering temperature (CP: charge-polarization, $\mathrm{ACP}$ : alternate charge-polarization); $T_{\mathrm{AO}}$ : anion-ordering temperature; GS: ground state (SP: spin-Peierls, AF: antiferromagnetic ordering, SS: anion-order-induced spin-singlet. The numbers in brackets represent the transition temperature); $P_{c}$ : critical pressure; $T_{\mathrm{c}}$ : critical temperature. ${ }^{\mathrm{b}}$ References for superconductivity. ${ }^{\mathrm{c}}$ Not measured. ${ }^{d}$ Not observed.

data revealed that the bands are more dispersive along the stacking direction $(/ / a)$ than along the side-by-side direction $(/ / b)$ and the Femi surface is composed of a wavy $1 \mathrm{D}$ hole-like surface along the $a$ axis (Fig. 15). Accordingly, the roomtemperature conductivity is the highest along the $a$ axis, and anisotropy is approximately $\sigma_{\mathrm{a}}: \sigma_{\mathrm{b}^{\prime}}: \sigma_{\mathrm{c}^{*}}=2000: 50: 1.68$ The formally three-quarter-filled HOMO band substantially splits into lower (bonding $\pi$ ) and upper (antibonding $\pi^{*}$ ) bands associated with the dimerized structure. Provided that $t_{2}$ is significantly higher than $U$ within a dimer, i.e., $U<4 t_{2}$, the upper band is regarded as a half-filled band with $W=0.45 \mathrm{eV}$. It is noteworthy that this value is significantly smaller than $1.70 \mathrm{eV}$ of an isolated $\mathrm{Pt}_{2}\left(\mathrm{MeCS}_{2}\right)_{4}$ l chain calculated using the first principles method within the density functional theory (DFT) under the assumption of the AV state. ${ }^{69}$ So far, five kinds of superconductors have been found for $(\mathrm{TMTTF})_{2} \mathrm{X} \quad\left(\mathrm{X}=\mathrm{PF}_{6}{ }^{-},{ }^{70,71} \mathrm{AsF}_{6}{ }^{-}\right.$(Fig. 16), ${ }^{72}$ $\mathrm{SbF}_{6}{ }^{-, 73} \mathrm{BF}_{4}^{-,},{ }^{74}$ and $\mathrm{Br}^{-75}$ ) by applying pressure above a few gigapascals (Table 1 ).

Herein, we have mainly described the structural and electronic properties of (TMTTF) ${ }_{2} \mathrm{PF}_{6}$ as an example of (TMTTF) ${ }_{2} \mathrm{X}$ formed with centrosymmetric octahedral anions because other relevant salts have qualitatively similar properties to those of (TMTTF) ${ }_{2} \mathrm{PF}_{6}$. (TMTTF) ${ }_{2} \mathrm{PF}_{6}$ shows metallic behavior under ambient conditions as a result of the three-quarter-filled conduction band. The conductivity is ca. $40 \mathrm{~S} \mathrm{~cm}^{-1}$ at room temperature and exhibits a maximum at around $245 \mathrm{~K}$ possibly due to the electronelectron correlations (AV state; Fig. 17(a)).62,76 The fact that the magnetic susceptibility shows no anomaly at around the temperature is indicative of the occurrence of separation between the spin and charge degrees of freedom in 1D electronic systems. ${ }^{77,78}$

On further cooling, the salt undergoes a phase transition to a $4 k_{\mathrm{F}}-\mathrm{CDW}$ CO state of Wigner crystal type (= CP; Fig. $17(\mathrm{~b}))$ at $67 \mathrm{~K}$, as observed via ${ }^{13} \mathrm{C} N M R,{ }^{79,80}$ dielectric, ${ }^{81}$ and optical spectroscopies. ${ }^{66,82}$ Band structure calculations of $(\mathrm{TMTTF})_{2} \mathrm{X}\left(\mathrm{X}=\mathrm{PF}_{6}{ }^{-}, \mathrm{AsF}_{6}{ }^{-}\right.$, and estimated to date.

Based on the IR spectroscopic study, the degree of charge disproportionation, $2 \delta$, which is defined as the difference between the charges of charge-rich and charge-poor TMTTF molecules, increases with the decrease in temperature below $67 \mathrm{~K}$ and eventually reaches 0.15 at $10 \mathrm{~K}$ (Fig. 18). ${ }^{66,84,85}$ The $2 \delta$ value is apparently smaller than those of (TMTTF) ${ }_{2} \mathrm{AsF}_{6}(0.21),{ }^{66}$ (TMTTF) $)_{2} \mathrm{SbF}_{6}(0.29),{ }^{66}$ and $(\mathrm{TMTTF})_{2} \mathrm{TaF}_{6}(0.28)^{84}$ with larger octahedral anions, presumably indicating that the chemical pressure induced by adopting smaller cations has a remarkable effect on the destabilization of the $\mathrm{CO}$ state. Additional (a) Averaged-valence (AV) state

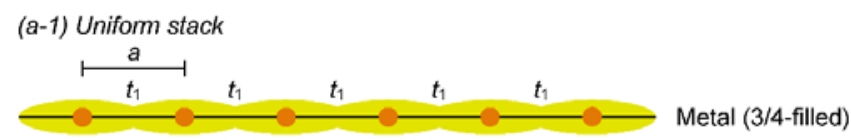

(a-2) Altemating stack

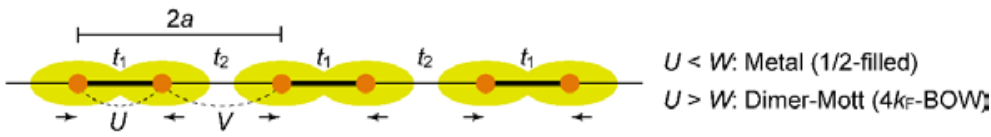

(b) Charge-polarization (CP) state

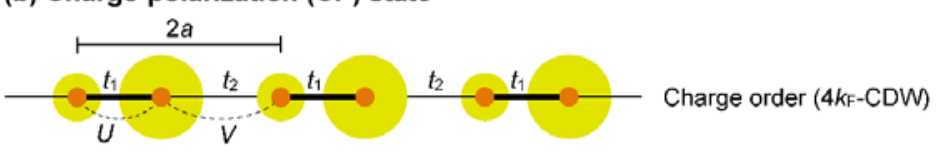

(c) Alternate charge-polarization (ACP) state

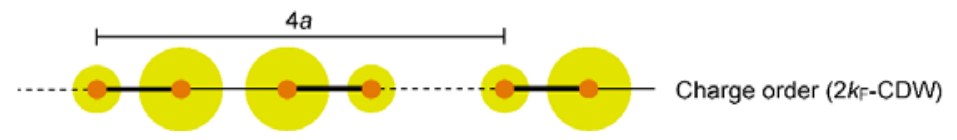

Fig. 17 Schematic electronic structures of typical states in (TMTTF) $)_{2} \mathrm{X}$, in which the average charge of TMTTF molecules is formally +0.5; (a) averaged-valence (AV) state in the cases of (a1) uniform stack and (a-2) alternating stack, (b) charge-polarization (CP) state, and (c) alternate charge-polarization (ACP) state ( $a$ : periodicity for the uniformly arranged AV state). Orange spheres indicate a TMTTF molecule, whereas the size of the yellow sphere/ellipses corresponds to the amount of charge on each TMTTF molecule. Note that the state in $(a-1)$ is not available for MMX-chain complexes due to the presence of bridging iodines. In (b) and (c), if the $4 k_{\mathrm{F}}$ and $2 k_{\mathrm{F}}$ modulations of electron density are accompanied by a lattice modulation (i.e., bond-order wave (BOW)), they can be described as " $4 k_{\mathrm{F}}-\mathrm{CDW}+4 k_{\mathrm{F}}-\mathrm{BOW}$ " and " $2 k_{\mathrm{F}}-\mathrm{CDW}+2 k_{\mathrm{F}}-\mathrm{BOW}$ " states, respectively. 


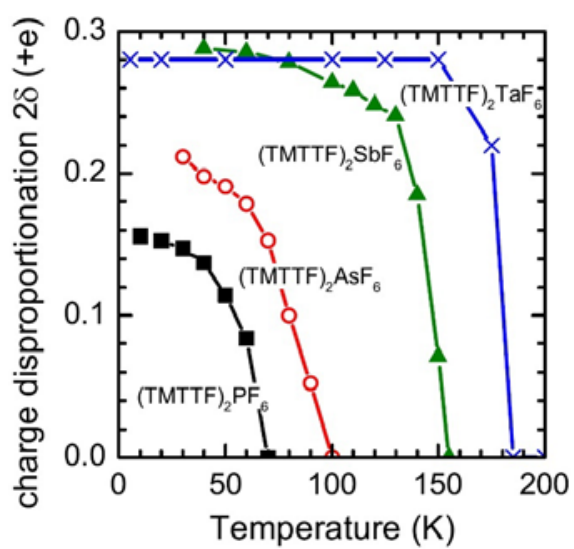

Fig. 18 Temperature dependence of the degree of charge disproportionation $(2 \delta)$ of (TMTTF $)_{2} \mathrm{X}$ with $\mathrm{X}=\mathrm{PF}_{6}{ }^{-}$(black closed squares), $\mathrm{AsF}_{6}{ }^{-}$(red open circles), $\mathrm{SbF}_{6}{ }^{-}$(green closed triangles), and $\mathrm{TaF}_{6}{ }^{-}$(blue crosses), estimated from the IR spectra. ${ }^{85}$

evidence of the effect of lattice compression on $2 \delta$ was provided by the rapid decrease in $2 \delta$ upon the application of pressure. $^{86}$

Herein, we have considered that the orientation of the $\mathrm{PF}_{6}{ }^{-}$ anions that are dynamically disordered on an inversion center becomes ordered at low temperatures. In this case, the space group changes from $P-1$ to $P 1$ due to the loss of the inversion center; however, the centrosymmetric nature of the anion disturbs the formation of any superstructure. It seems reasonable that the charges of two crystallographically independent TMTTF molecules in a unit cell deviate from the average charge of +0.5 , i.e., $+(0.5+\delta)$ and $+(0.5-\delta)$, causing a $C P$ type CO pattern. However, structural alternation in the stacking columns corresponding to the $\mathrm{CO}$ state could not be appreciably detected in crystallographic studies, although symmetry breaking was observed in the NMR spectra. ${ }^{79}$ Therefore, the CO transition was temporarily considered as a "structureless" transition. ${ }^{87}$ The first evidence of relevant structural modulation was recently found via synchrotron X-ray diffraction measurements, ${ }^{88}$ which is not only the same as that previously

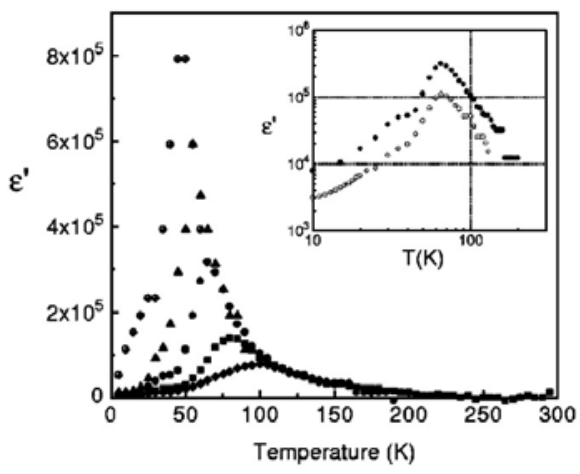

Fig. 19 Temperature dependence of the real part of the dielectric permittivity $\left(\varepsilon^{\prime}\right)$ of (TMTTF) ${ }_{2} \mathrm{PF}_{6}$ at different frequencies: $1 \mathrm{kHz}(\oplus), 10 \mathrm{kHz}$ $(\boldsymbol{\Delta}), 100 \mathrm{kHz}(\bullet), 1 \mathrm{MHz}(\mathbf{\bullet})$, and $5 \mathrm{MHz}(\bullet)$. Inset shows the difference between the $\varepsilon^{\prime}$ of the salt obtained from different batches $(100 \mathrm{kHz})$. Adapted with permission from ref. 92. Copyright 2000 American Physical Society. considered based on experimental (ESR) ${ }^{89}$ and theoretical ${ }^{90,91}$ studies, but also implies the formation of a 2D Wigner lattice. In such a 2D layer (within the $a b$ plane), charge-rich TMTTF molecules with ca. +0.6 charge are preferably arranged so as not to be contiguous to each other as a consequence of long-range Coulomb repulsions (sum of the on-site $(U)$ and inter-site $(V)$ Coulomb repulsions).

Dielectric permittivity measurements show a peak divergence in the real part of the dielectric constant for (TMTTF) ${ }_{2} \mathrm{PF}_{6}$ (Fig. 19), ${ }^{92}$ (TMTTF) ${ }_{2} \mathrm{AsF}_{6},{ }^{93}$ and (TMTTF) ${ }_{2} \mathrm{SbF}_{6}{ }^{81}$ at each transition temperature. The unusual dielectric response that has a broad peak as a function of temperature and is strictly frequencydependent bears the clear signatures of relaxor ferroelectrics, typical of the glass-like freezing of short-range ferroelectric ordering. It is noteworthy that the ground state varies depending on the anions; i.e., spin-Peierls state in (TMTTF ${ }_{2} \mathrm{PF}_{6}$ and $(\mathrm{TMTTF})_{2} \mathrm{AsF}_{6}$ and antiferromagnetic ordered state in (TMTTF) ${ }_{2} \mathrm{SbF}_{6}{ }^{3,14,39}$ Theoretical study predicted that the $\mathrm{CP}$ type $\mathrm{CO}$ state (including $4 k_{\mathrm{F}}-\mathrm{CDW}$ ) stabilized by the increase in $V$ inhibits the spin-Peierls transition (including $2 k_{\mathrm{F}}-\mathrm{BOW}$; Fig. $20(a)$ ), and therefore, (TMTTF) ${ }_{2} \mathrm{SbF}_{6}$, which has a more stable $\mathrm{CO}$ state with a higher charge-ordering temperature, undergoes an antiferromagnetic transition (Fig. 20(b)) in place of a spinPeierls transition at low temperatures. ${ }^{94}$

(a) Spin-Peierls state

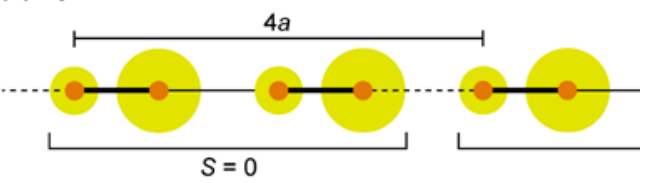

(b) Antiferromagnetic ordered state

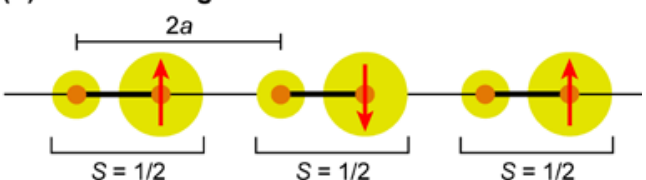

Fig. 20 Schematic electronic structures of (a) spin-Peierls state in (TMTTF $)_{2} \mathrm{PF}_{6}$ and $(\mathrm{TMTTF})_{2} \mathrm{AsF}_{6}$ and (b) antiferromagnetic ordered state in (TMTTF) ${ }_{2} \mathrm{SbF}_{6}{ }^{94}$ Red arrows indicate a magnetically ordered spin, and other specifications are the same as those used in Fig. 17.

Next, the structural and physical properties of (TMTTF) ${ }_{2} \mathrm{ReO}_{4}$ as an example of (TMTTF) ${ }_{2} \mathrm{X}$ formed with noncentrosymmetric tetrahedral anions have been described. (TMTTF) ${ }_{2} \mathrm{ReO}_{4}$ has a room-temperature conductivity of ca. $20 \mathrm{~S} \mathrm{~cm}^{-1}$ and shows metallic behavior down to ca. $230 \mathrm{~K}, 87$ at which it undergoes a $2 k_{\mathrm{F}}-\mathrm{CDW}$ CO (= ACP; Fig. $17(\mathrm{c})$ ) transition observed by various techniques such as X-ray diffraction, ${ }^{83,95} \mathrm{ESR}^{89}$ and $\mathrm{NMR}^{96}$ measurements. The noncentrosymmetric $\mathrm{ReO}_{4}^{-}$anions are randomly orientated at room temperature, and the orientational disorder is frozen over two (or more) equivalent orientations upon cooling. An X-ray diffuse scattering study revealed that (TMTTF) ${ }_{2} \mathrm{ReO}_{4}$ undergoes a first-order structural phase transition associated with anion ordering at $157 \mathrm{~K}$, at which a superstructure with a critical wave vector $\boldsymbol{q}_{\mathrm{AO}}=$ $(1 / 2,1 / 2,1 / 2)$ to form a $2 k_{\mathrm{F}}$ modulation within the $\pi$-stacking columns becomes pronounced. ${ }^{97}$ This transition is accompanied by the displacement of the anions, which results in the sizeable tetramerization of the TMTTF molecules within the column to 
stabilize the $2 k_{\mathrm{F}}-\mathrm{CDW}$ CO state $(2 \delta=0.35$ at $200 \mathrm{~K}$ and 0.64 at $40 \mathrm{~K}){ }^{98}$ At present, the precise reason why (TMTTF) ${ }_{2} \mathrm{ClO}_{4}$ does not undergo a $\mathrm{CO}$ transition at low temperatures is not fully established; however, it is possible that the occurrence of anion ordering $(73 \mathrm{~K})$ prior to charge ordering causes spin-singlet formation due to doubled periodicity along the stacking direction. As shown in ref. 83, the degree of dimerization of (TMTTF $)_{2} \mathrm{ClO}_{4}$ is relatively independent of temperature and remains at a high level, which can affect the suppression of the $\mathrm{CO}$ state. ${ }^{29}$ It must be true that the symmetry of counter anions is responsible for determining the $\mathrm{CO}$ pattern, whether $\mathrm{CP}$ or ACP, in the TMTTF $\pi$-stacking column (Table 1 ). To date, a successive phase transition from the $A V$ to $A C P$ state passing through the CP state on cooling, as observed for $\mathrm{Pt}_{2}\left(\mathrm{RCS}_{2}\right)_{4} \mathrm{l}$, has not been reported for (TMTTF) ${ }_{2} \mathrm{X}$.

(TMTTF) ${ }_{2} \mathrm{X}$ formed with another type of noncentrosymmetric anion, linear $\mathrm{SCN}^{-}$, exhibits some similarities with (TMTTF) ${ }_{2} \mathrm{ReO}_{4}$ in addition to striking differences. With decreasing temperature, (TMTTF) ${ }_{2} \mathrm{SCN}$ also undergoes a structural phase transition due to anion ordering at $160 \mathrm{~K} .{ }^{99}$ However, the superstructure is equal to $\boldsymbol{q}_{\mathrm{AO}}=(0,1 / 2,1 / 2)$, indicating that the CO pattern is of $4 k_{\mathrm{F}}-\mathrm{CDW}$-type $(=\mathrm{CP})$, as in the case of $(\mathrm{TMTTF})_{2} \mathrm{PF}_{6}$, because of no phase modulation within the $\pi$-stacking column. On further cooling, (TMTTF) ${ }_{2} \mathrm{SCN}$ undergoes antiferromagnetic ordering below $7 \mathrm{~K}$, whereas (TMTTF) ${ }_{2} \mathrm{PF}_{6}$ and $(\mathrm{TMTTF})_{2} \mathrm{ReO}_{4}$ show a pronounced phase transition to nonmagnetic ground states arising from the spin-Peierls transition at $15 \mathrm{~K}$ and anion-orderinduced tetramerization at $157 \mathrm{~K}$, respectively. ${ }^{3,14,39}$

As described above, the application of pressure modifies the CO behavior and also bring the salts into the 3D ordered electronic states such as antiferromagnetic ordered and superconducting states. Pressure dependence of the $\mathrm{CO}$ transition was investigated by ${ }^{13} \mathrm{C}$ NMR spectroscopy. ${ }^{100,101}$ For example, the $\mathrm{CO}$ transition temperature of (TMTTF $)_{2} \mathrm{AsF}_{6}$, which appears to be $102 \mathrm{~K}$ under ambient pressure, dramatically decreases with increasing pressure and eventually disappears under a pressure of $0.15 \mathrm{GPa} .{ }^{100}$ Such a suppression of the $\mathrm{CO}$ state, as observed for $\mathrm{Pt}_{2}\left(\mathrm{EtCS}_{2}\right)_{4}$ l below $2.2 \mathrm{GPa}$ (Fig. 8), ${ }^{32}$ is possibly a reflection of the increased $W$ compared with $V$.

In the generic phase diagram of (TMTTF) $)_{2} X$ and (TMTSF) $)_{2} X$ systems shown in Fig. 13, which was originally proposed by Jérome ${ }^{13,102}$ and subsequently made more sophisticated by Dressel,39,66 "loc" (as Mott insulating state), “1D", and "2D" regimes are defined on the basis of the anisotropy of transport behavior as " $\mathrm{d} \rho_{\mathrm{a}} / \mathrm{d} T<0$ and $\mathrm{d} \rho_{\mathrm{c}} / \mathrm{d} T<0$ ", " $\mathrm{d} \rho_{\mathrm{a}} / \mathrm{d} T>0$ and $\mathrm{d} \rho_{\mathrm{c}} / \mathrm{d} T$ $<0$ ", and " $\mathrm{d} \rho_{\mathrm{a}} / \mathrm{d} T>0$ and $\mathrm{d} \rho_{\mathrm{c}} / \mathrm{d} T>0$ ", respectively, ${ }^{103}$ where the $a$ and $c$ axes correspond to the most- and least-conducting directions, respectively. Therefore, the boundary between the "loc" and "1D" regimes is determined as a temperature at which the conductivity along the $a$ axis exhibits a maximum (A charge gap $\left(\Delta_{\rho}\right)$ estimated from the slope of the Arrhenius plot is often substituted for the temperature due to thermal inaccessibility). Furthermore, the temperature at which the conductivity along the $c$ axis exhibits a maximum provides a crossover between the "1D" and "2D" regimes and is therefore regarded as the Mott transition temperature (or Mott-Hubbard gap). ${ }^{104}$ The crossover between the " $2 \mathrm{D}$ " and " $3 \mathrm{D}$ " regimes, which is only available for the (TMTSF) ${ }_{2} \mathrm{X}$ system, is defined as the upper limit for a low-temperature 3D coherent domain. ${ }^{105}$ The metalinsulator transition temperature is gradually decreased upon applying pressure possibly because of the decrease in the onsite Coulomb repulsion. This trend is exactly opposite to that found for $\mathrm{Pt}_{2}\left(\mathrm{RCS}_{2}\right)_{4} \mathrm{I}(\mathrm{R}=\mathrm{Me}$ and $\mathrm{Et}), 32,37$ although the electronic states just below the metal-insulator transition might be different in kind from each other. Increased electronic dimensionality in addition to the significant lattice compression may modify the electronic state in the favorable direction of a stabilized metallic phase. In fact, the calculated dimensionality parameter, defined as the ratio of inter-column $(t \perp)$ and intracolumn $(t / /)$ transfer energies, increases with increasing applied pressure and decreasing temperature (Fig. 21). ${ }^{106}$ Therefore, it is most likely that on cooling, $\mathrm{Pt}_{2}\left(\mathrm{RCS}_{2}\right)_{4}$ l with a strong $1 \mathrm{D}$ character moves towards the lower left direction instead of towards the beneath direction under a certain pressure in the phase diagram shown in Fig. 13. Although the 1D character disturbs the antiferromagnetic ordering due to quantum fluctuations, the metal-insulator transition followed by the emergence of the CO state, as observed for most $\mathrm{Pt}_{2}\left(\mathrm{RCS}_{2}\right)_{4} \mathrm{l}$, seems to be consistent with this possible movement.
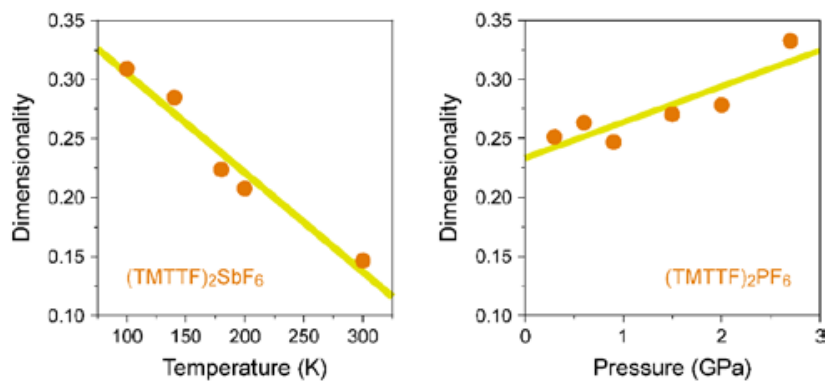

Fig. 21 (a) Temperature dependence of dimensionality (see text) of (TMTTF) ${ }_{2} \mathrm{SbF}_{6}$ and (b) pressure dependence of dimensionality of (TMTTF) ${ }_{2} \mathrm{PF}_{6}$ (data obtained from ref. 106). Yellow lines are guides to the eye.

It is fair to say that all (TMTTF) ${ }_{2} \mathrm{X}$ salts reside in the Luttingerliquid regime at high temperatures because of their 1D electronic character. Herein, we focused on the inter-column $(/ / c)$ transport behavior in the insulating regime, because the temperature dependence of the resistivity is described by the Luttinger liquid model: $\rho_{\mathrm{c}} \sim T^{1-2 \alpha}, \alpha=1 / 4\left(K_{\rho}+K_{\rho}^{-1}-2\right)$, where $K_{\rho}$ is the Luttinger parameter (cf., $\rho_{\mathrm{a}} \sim T^{16 K \rho-3}$ at $T>\Delta_{\rho}$ for quarterfilled system). ${ }^{67}$ An electronic system with stronger repulsive energies affords a lower $K_{\rho}$, and the critical value for Mott transition varies depending on the order of commensurability $\left(K_{\rho}{ }^{*}=1 / n^{2} ; n=1\right.$ for half-filled system and $n=2$ for quarterfilled system). Clearly, the low $K_{\rho}$ values observed for $(\mathrm{TMTTF})_{2} \mathrm{PF}_{6}(0.18)^{104}$ and $(\mathrm{TMTTF})_{2} \mathrm{AsF}_{6}(0.20)^{107}$ are associated with the quarter-filled $\mathrm{HOMO}$ band. Since the $K_{\rho}$ values are close to 0.25 above which quarter-filled umklapp scattering is irrelevant, it is apparent that these salts are just on the insulating side of the boundary between the TomonagaLuttinger liquid and 1D Mott insulating state. Selenium substitution (TMTTF to TMTSF) ${ }^{103}$ and application of pressure ${ }^{108}$ rapidly bring these salts into the metallic regime with higher $K_{\rho}$ values.

\section{Outlook and Conclusions}

The 1D electronic subclass of metal-complex and molecular solids is very broad, and we have only covered the most informative examples in this review. As mentioned above, the half-filled band with antibonding character, which arises from 
the monocationic dimers as units, leads to the pronounced interdimer interactions owing to the orbital expanding towards the outside of dimers. The increased $W$ as well as the decreased $U$ owing to the dimer formation is considered to be the primary cause for the comparable $U$ and $W$, which bring the solids into the vicinity of Mott boundary. Although the chemical modification of TMTTF molecules causes a dramatical change in the molecular arrangement in the cation radical salts, the basic structure of MMX-chain complexes remains unchanged because of the covalent bonding between the binuclear metal subunits through the bridging halogens. Considering the fact that the functional groups attached to the dithiocarboxylate ligands in MMX-chain complexes remain rather limited to $n$ alkyl (from methyl to $n$-hexyl) groups, attaching other functional groups to impart desired functionalities and longer alkyl groups that serve as van der Waals interaction sites may provide a significant step forward in exploring more versatile electronic materials, apart from the difficulty in synthesizing the ligands. Additionally, the subunits that are separated from each other by a bridging halogen are beneficial not only for the full substitution of $\mathrm{Pt}$ with $\mathrm{Ni}, 109,110$ but also for the partial substitution of Pt to afford heterobimetallic subunits PtM (M = $\mathrm{Ni}$ and $\mathrm{Pd}$ ). ${ }^{111}$ Such a replacement while maintaining the basic structure is not simply possible in (TMTTF) ${ }_{2} X$, in which the columnar assembly of TMTTF molecules is achieved mainly by the weak $\pi-\pi$ interactions.

The principal advantage of (TMTTF) ${ }_{2} \mathrm{X}$ over the MMX-chain complexes might be the tunability of their electronic properties by chemical or physical pressure, which is mainly attributed to the softness of the lattice. The appearance of 3D ordered electronic states such as antiferromagnetic ordered and superconducting states that are not yet found in MMX-chain complexes can best be thought of as a manifestation of the intermolecular $\pi-\pi$ and van der Waals interactions as dominant structure-directing forces. Additionally, by studying the relative properties of a variety of (TMTTF) ${ }_{2} \mathrm{X}$, a broad picture of the electronic behavior of this system has depicted not only the 1D regime but also the 1D-2D dimensional crossover regime. We hope that this review, which compares the structural and electronic properties of metal-chain complexes and organic conductors to provide insights into the relevant issues that are currently under debate, will stimulate further experimental and theoretical explorations of new and more advanced electronic materials that might surpass the existing electronic materials.

\section{Conflicts of interest}

There are no conflicts to declare.

\section{Acknowledgements}

The authors are grateful to Dr. Toshikazu Nakamura (Institute for Molecular Science, Japan) and Dr. Kenji Yonemitsu (Chuo University, Japan) for their helpful discussion. We also thank Dr. Nakamura for providing crystallographic data. This feature article is dedicated to the memory of the late Prof. Peter Day, who passed away on May 19, 2020.

\section{Notes and references}

1 P. Day, Mixed Valence Chemistry and Metal Chain Compounds in Low-Dimensional Cooperative Phenomena, ed. H. Keller, Plenum, New York, 1975, pp. 191-214.

2 Extended Linear Chain Compounds, ed. E. Conwell, ed. J. S. Miller, Plenum Press, New York, 1982.

3 T. Ishiguro, K. Yamaji and G. Saito, Organic Superconductors, 2nd edn., Springer-Verlag, Berlin, 1998.

4 J. W. Bray, H. R. Hart, Jr., L. V. Interrante, I. S. Jacobs, J. S. Kasper, G. D. Watkins, S. H. Wee and J. C. Bonner, Phys. Rev. Lett., 1975, 35, 744.

5 M. Hase, I. Terasaki and K. Uchinokura, Phys. Rev. Lett., 1993, 70, 3651.

6 K. Krogmann and H. D. Hausen, Z. Anorg. Allg. Chem., 1968, 358, 67.

7 H. R. Zeller and A. Beck, J. Phys. Chem. Solids, 1974, 35, 77.

8 J. P. Ferraris, D. O. Cowan, V. Walatka, Jr. and J. H. Perlstein, J. Am. Chem. Soc., 1973, 95, 948.

9 L. B. Coleman, M. J. Cohen, D. J. Sandman, F. G. Yamagishi, A. F. Garito and A. J. Heeger, Solid State Commun., 1973, 12, 1125.

10 Semiconductors and Semimetals, ed. E. Conwell, Academic Press, San Diego, 1988, vol. 27.

11 K. Nasu, J. Phys. Soc. Jpn., 1983, 52, 3865

12 Material Designs and New Physical Properties in MX- and MMX-Chain Compounds, ed. M. Yamashita and H. Okamoto, Springer-Verlag, Wien, 2013.

13 D. Jérome, Chem. Rev., 2004, 104, 5565.

14 J.-P. Pouget, P. Alemany and E. Canadell, Mater. Horiz., 2018, 5,590 .

15 H. Wolffram, Dissertation, Königsberg, 1900.

16 B. K. Chakraverty, J. Phys. (Paris) Lett., 1979, 40, L99.

17 M. B. Robin and P. Day, Adv. Inorg. Chem. Radiochem., 1967, 10, 247.

18 H. Kitagawa, N. Onodera, T. Sonoyama, M. Yamamoto, T. Fukuwa, T. Mitani, M. Seto and Y. Maeda, J. Am. Chem. Soc., 1999, 121, 10068.

19 C. Bellitto, A. Flamini, L. Gastaldi and L. Scaramuzza, Inorg. Chem., 1983, 22, 444.

20 M. Yamashita, S. Takaishi, A. Kobayashi, H. Kitagawa, H. Matsuzaki and H. Okamoto, Coord. Chem. Rev., 2006, 250, 2335.

21 H. Iguchi, S. Takaishi and M. Yamashita, Chem. Lett., 2014, 43, 69.

22 J. Grote, F. Friedrich, K. Berthold, L. Hericks, B. Neumann, H.G. Stammler and N. W. Mitzel, Chem. Eur. J., 2018, 24, 2626.

23 H. Kitagawa, N. Onodera, J.-S. Ahn, T. Mitani, M. Kim, Y. Ozawa, K. Toriumi, K. Yasui, T. Manabe and M. Yamashita, Mol. Cryst. Liq. Cryst., 1996, 285, 311.

24 H. Kitagawa, N. Onodera, J.-S. Ahn, T. Mitani, K. Toriumi and M. Yamashita, Synth. Met., 1997, 86, 1931.

25 H. Kitagawa and T. Mitani, Coord. Chem. Rev., 1999, 190-192, 1169.

26 S. A. Borshch, K. Prassides, V. Robert and A. O. Solonenko, J. Chem. Phys., 1998, 109, 4562.

27 S. Yamamoto, J. Phys. Soc. Jpn., 2001, 70, 1198.

28 S. Yamamoto, J. Phys. Chem. Solids, 2002, 63, 1489.

29 M. Tsuchiizu, H. Yoshioka and Y. Suzumura, J. Phys. Soc. Jpn., 2001, 70, 1460.

30 M. Kuwabara and K. Yonemitsu, J. Mater. Chem., 2001, 11, 2163.

31 M. Mitsumi, T. Murase, H. Kishida, T. Yoshinari, Y. Ozawa, K. Toriumi, T. Sonoyama, H. Kitagawa and T. Mitani, J. Am. Chem. Soc., 2001, 123, 11179.

32 K. Otsubo, A. Kobayashi, M. Hedo, Y. Uwatoko and H. Kitagawa, Chem. Asian J., 2009, 4, 1673.

33 M. Mitsumi, K. Kitamura, A. Morinaga, Y. Ozawa, M. Kobayashi, K. Toriumi, Y. Iso, H. Kitagawa and T. Mitani, Angew. Chem. Int. Ed., 2002, 41, 2767. 
34 A. Kobayashi, S. Kitao, M. Seto, R. Ikeda and H. Kitagawa, Inorg. Chem., 2009, 48, 8044.

35 H. Tanaka, S. Kuroda, et al., to be submitted.

36 K. Otsubo, A. Kobayashi, H. Kitagawa, M. Hedo, Y. Uwatoko, H. Sagayama, Y. Wakabayashi and H. Sawa, J. Am. Chem. Soc. 2006, 128, 8140.

37 K. Otsubo, T. Suto, A. Kobayashi, R. Ikeda, M. Hedo, Y. Uwatoko and H. Kitagawa, Eur. J. Inorg. Chem., 2016, 27, 4402.

38 L. Degiorgi and D. Jérome, J. Phys. Soc. Jpn., 2006, 75, 051004.

39 M. Dressel, Naturwissenschaften, 2007, 94, 527.

40 K. Saito, S. Ikeuchi, Y. Nakazawa, A. Sato, M. Mitsumi, T. Yamashita, K. Toriumi and M. Sorai, J. Phys. Chem. B, 2005, 109, 2956.

41 A. Guijarro, O. Castillo, L. Welte, A. Calzolari, P. J. S. Miguel, C. J. Gómez-García, D. Olea, R. di Felice, J. Gómez-Herrero and F. Zamora, Adv. Funct. Mater., 2010, 20, 1451.

42 M. Mitsumi, T. Yamashita, Y. Aiga, K. Toriumi, H. Kitagawa, T. Mitani and M. Kurmoo, Inorg. Chem., 2011, 50, 4368.

43 M. Mitsumi, S. Umebayashi, Y. Ozawa, K. Toriumi, H. Kitagawa and T. Mitani, Chem. Lett., 2002, 31, 258.

44 A. Ota, L. Ouahab, S. Golhen, Y. Yoshida, M. Maesato, G. Saito and R. Świetlik, Chem. Mater., 2007, 19, 2455.

45 P. Le Maguerès, L. Ouahab, P. Briard, J. Even, M. Bertault, L. Toupet, J. Ramos, C. J. Gomez-García and P. Delhaès, Mol. Cryst. Liq. Cryst., 1997, 305, 479.

46 T. Kakiuchi, Y. Wakabayashi, H. Sawa, T. Takahashi and T. Nakamura, J. Phys. Soc. Jpn., 2007, 76, 113702.

47 Y. Miyazaki, Q. Wang, A. Sato, K. Saito, M. Yamamoto, H. Kitagawa, T. Mitani and M. Sorai, J. Phys. Chem. B, 2002, 106, 197.

48 S. Ikeuchi, K. Saito, Y. Nakazawa, A. Sato, M. Mitsumi, K. Toriumi and M. Sorai, Phys. Rev. B, 2002, 66, 115110.

49 S. Ikeuchi, K. Saito, Y. Nakazawa, M. Mitsumi, K. Toriumi and M. Sorai, J. Phys. Chem. B, 2004, 108, 387.

50 M. Sorai, M. Nakano and Y. Miyazaki, Chem. Rev., 2006, 106 976.

51 S. Ikeuchi, Y. Yamamura, M. Mitsumi, K. Toriumi, H. Saitoh, T. Atake and K. Saito, Chem. Lett., 2009, 38, 1190.

52 G. Saito and Y. Yoshida, Bull. Chem. Soc. Jpn., 2007, 80, 1.

53 G. Saito and Y. Yoshida, Chem. Record, 2011, 11, 124.

54 J. M. Williams, A. J. Schultz, U. Geiser, K. D. Carlson, A. M. Kini, H. H. Wang, W.-K. Kwok, M.-H. Whangbo and J. E. Schirber, Science, 1991, 252, 1501.

55 U. Geiser and J. A. Schlueter, Chem. Rev., 2004, 104, 5203.

56 H. Kitagawa, S. Nakagami and T. Mitani, Synth. Met., 2001, 116, 401.

57 K. Furukawa, T. Hara and T. Nakamura, J. Phys. Soc. Jpn., 2009, 78, 104713

58 E. Rose, C. Loose, J. Kortus, A. Pashkin, C. A. Kuntscher, S. G. Ebbinghaus, M. Hanfland, F. Lissner, Th. Schleid and M. Dressel, J. Phys.: Condens. Matter, 2013, 25, 014006.

59 J. P. Ferraris, T. O. Poehler, A. N. Bloch and D. O. Cowan, Tetrahedron Lett., 1973, 14, 2553.

60 A. Mas, J.-M. Fabre, E. Torreilles, L. Giral and G. Brun, Tetrahedron Lett., 1977, 18, 2579.

61 J.-M. Fabre, C. Galaine and L. Giral, J. Phys. Colloq., 1983, 44, C3-1153.

62 P. Delhaes, C. Coulon, J. Amiell, S. Flandrois, E. Toreilles, J.-M. Fabre and L. Giral, Mol. Cryst. Liq. Cryst., 1979, 50, 43.

63 G. Brun, B. Liautard, S. Peytavin, M. Maurin, E. Toreilles, J.-M. Fabre, L. Giral and J. L. Galigné, J. Phys. Colloq., 1977, 38, C7266.

64 D. Jérome, A. Mazaud, M. Ribault and K. Bechgaard, J. Phys. Lett., 1980, 41, L95.

65 K. Bechgaard, K. Carneiro, F. B. Rasmussen and M. Olsen, J. Am. Chem. Soc., 1981, 103, 2440.

66 M. Dressel, M. Dumm, T. Knoblauch and M. Masino, Crystals, 2012, 2, 528
67 T. Giamarchi, Chem. Rev., 2004, 104, 5037.

68 B. Köhler, E. Rose, M. Dumm, G. Untereiner and M. Dressel, Phys. Rev. B, 2011, 84, 035124.

69 A. Calzolari, S. S. Alexandre, Felix Zamora and R. di Felice, J. Am. Chem. Soc., 2008, 130, 5552.

70 T. Adachi, E. Ojima, K. Kato, H. Kobayashi, T. Miyazaki, M. Tokumoto and A. Kobayashi, J. Am. Chem. Soc., 2000, 122, 3238.

71 D. Jaccard, H. Wilhelm, D. Jérome, J. Moser, C. Carcel and J.M. Fabre, J. Phys.: Condens. Matter, 2001, 13, L89.

72 M. Itoi, M. Kano, N. Kurita, M. Hedo, Y. Uwatoko and T. Nakamura, J. Phys. Soc. Jpn., 2007, 76, 053703.

73 M. Itoi, C. Araki, M. Hedo, Y. Uwatoko and T. Nakamura, J. Phys. Soc. Jpn., 2008, 77, 023701.

74 P. Auban-Senzier, C. Pasquier, D. Jérome, C. Carcel and J.-M Fabre, Synth. Met., 2003, 133-134, 11.

75 L. Balicas, K. Behnia, W. Kang, P. Auban-Senzier, E. Canadell, D. Jérome, M. Ribault and J.-M. Fabre, Adv. Mater., 1994, 6, 762.

76 M. Dressel, S. Kirchner, P. Hesse, G. Untereiner, M. Dumm, J. Hemberger, A. Loidl and L. Montgomery, Synth. Met. 2001, 120, 719.

77 C. Coulon, P. Delhaes and S. Flandrois, J. Physique, 1982, 43 1059.

78 M. Dumm, A. Loidl, B. W. Fravel, K. P. Starkey, L. K. Montgomery and M. Dressel, Phys. Rev. B, 2000, 61, 511.

79 D. S. Chow, F. Zamborszky, B. Alavi, D. J. Tantillo, A. Baur, C. A. Merlic and S. E. Brown, Phys. Rev. Lett., 2000, 85, 1698.

80 T. Nakamura, K. Furukawa and T. Hara, J. Phys. Soc. Jpn., 2007 76, 064715 .

81 P. Monceau, F. Ya. Nad and S. Brazovskii, Phys. Rev. Lett., 2001, 86, 4080.

82 M. Dumm, M. Abaker and M. Dressel, J. Phys. IV (France), 2005, 131, 55.

83 Y. Nogami, T. Ito, K. Yamamoto, N. Irie, S. Horita, T. Kambe, N. Nagao, K. Oshima, N. Ikeda and T. Nakamura, J. Phys. IV (France), 2005, 131, 39

84 Y. Oka, N. Matsunaga, K. Nomura, A. Kawamoto, K. Yamamoto and K. Yakushi, J. Phys. Soc. Jpn., 2015, 84, 114709.

85 T. Peterseim and M. Dressel, Crystals, 2017, 7, 278.

86 I. Voloshenko, M. Herter, R. Beyer, A. Pustogow and M. Dressel, J. Phys.: Condens. Matter, 2017, 29, 115601.

87 C. Coulon, S. S. P. Parkin and R. Laversanne, Phys. Rev. B, 1985 31, 3583.

88 S. Kitou, T. Fujii, T. Kawamoto, N. Katayama, S. Maki, E. Nishibori, K. Sugimoto, M. Takata, T. Nakamura and H. Sawa, Phys. Rev. Lett., 2017, 119, 065701.

89 T. Nakamura, J. Phys. Soc. Jpn., 2003, 72, 213.

90 H. Seo and H. Fukuyama, J. Phys. Soc. Jpn., 1997, 66, 1249.

91 S. Mazumdar, R. T. Clay and D. K. Campbell, Phys. Rev. B, 2000 62, 13400 .

92 F. Nad, P. Monceau, C. Carcel and J.-M. Fabre, Phys. Rev. B, $2000,62,1753$.

93 F. Nad, P. Monceau, C. Carcel and J.-M. Fabre, J. Phys. Condens. Matter, 2000, 12, L435.

94 K. Yoshimi, H. Seo, S. Ishibashi and S. E. Brown, Phys. Rev. Lett, 2012, 108, 096402.

95 Y. Nogami and T. Nakamura, J. Phys. IV (France), 2002, 12, Pr9145.

96 T. Nakamura, K. Furukawa and T. Hara, J. Phys. Soc. Jpn., 2006 75, 013707

97 S. S. P. Parkin, J. J. Mayerle and E. M. Engler, J. Phys. Colloq. 1983, 44, C3-1105.

98 A. Pustogow, T. Peterseim, S. Kolatschek, L. Engel and M. Dressel, Phys. Rev. B, 2016, 94, 195125

99 C. Coulon, A. Maaroufi, J. Amiell, E. Dupart, S. Flandrois, P. Delhaes, R. Moret, J. P. Pouget and J. P. Morand, Phys. Rev. B, 1982, 26, 6322 . 
100 F. Zamborszky, W. Yu, W. Raas, S. E. Brown, B. Alavi, C. A. Merlic and A. Baur, Phys. Rev. B, 2002, 66, 081103.

101 W. Yu, F. Zhang, F. Zamborszky, B. Alavi, A. Baur, C. A. Merlic and S. E. Brown, Phys. Rev. B, 2004, 70, 121101.

102 D. Jérome, Science, 1991, 252, 1509.

103 J. Moser, M. Gabay, P. Auban-Senzier, D. Jérome, K. Bechgaard and J.-M. Fabre, Eur. Phys. J. B, 1998, 1, 39.

104 P. Auban-Senzier, D. Jérome, C. Carcel and J.-M. Fabre, J. Phys. IV (France), 2004, 114, 41.

105 P. Auban-Senzier, D. Jérome, N. Doiron-Leyraud, S. René de Cotret, A. Sedeki, C. Bourbonnais, L. Taillefer, P. Alemany, E. Canadell and K. Bechgaard, J. Phys.: Condens. Matter, 2011, 23, 345702.

106 A. C. Jacko, H. Feldner, E. Rose, F. Lissner, M. Dressel, R. Valentí and H. O. Jeschke, Phys. Rev. B, 2013, 87, 155139.

107 B. Korin-Hamzić, E. Tafra, M. Basletić, A, Hamzić and M. Dressel, Phys. Rev. B, 2006, 73, 115102.

108 A. Pashkin, M. Dressel and C. A. Kuntscher, Phys. Rev. B, 2006, 74, 165118.

109 C. Bellitto, G. Dessy and V. Fares, Inorg. Chem., 1985, 24, 2815.

110 M. Mitsumi, Y. Youshida, A. Kohyama, Y. Kitagawa, Y. Ozawa, M. Kobayashi, K. Toriumi, M. Tadokoro, N. Ikeda, M. Okumura and M. Kurmoo, Inorg. Chem., 2009, 48, 6680.

111 G. Givaja, O. Castillo, E. Mateo, A. Gallego, C. J. GómezGarcía, A. Calzolari, R. di Felice and F. Zamora, Chem. Eur. J., 2012, 18, 15476. 